\title{
LEVERAGING RHETORICAL STYLE TO REDUCE THE EXISTENTIAL THREAT OF INCLUSIVE MESSAGING
}

A Dissertation
presented to
the Faculty of the Graduate School
at the University of Missouri-Columbia
In Partial Fulfillment
of the Requirements for the Degree
Doctor of Philosophy
JAKE WOMICK
Dr. Laura A. King, Dissertation Supervisor
MAY 2021


The undersigned, appointed by the dean of the Graduate School, have examined the Dissertation entitled

\section{LEVERAGING RHETORICAL STYLE TO REDUCE THE EXISTENTIAL THREAT OF INCLUSIVE MESSAGING}

presented by Jake Womick, a candidate for the degree of Doctor of Philosophy of Social and Personality Psychology, and hereby certify that, in their opinion, it is worthy of acceptance.

Professor Laura King

Professor Ann Bettencourt

Professor Jamie Arndt

Professor Amanda Rose

Professor Rebecca Scott 


\section{ACKNOWLEDGEMENTS}

This dissertation was made possible by a number of significant figures in my life. Most importantly, my wife, Ally. Ally has supported me in every way imaginable over the last decade. She gives me the strength to be vulnerable, compassionate, and to pursue the best version of myself. I certainly would not have the capacity to be the scholar (or the person) I am without her. We were together long before I entered graduate school. We were always aware that finishing my dissertation meant a move for us to some unknown location in the country or the world. We now know that next step will be moving to North Carolina. It is both exciting and frightening. Words can not do justice to my gratitude for your commitment to me, and your willingness to move half-way across the country with me. I look forward to the fun, challenges, and growth we will experience together as we pursue this next chapter in our lives.

My family (especially mom, dad, Zoey, Mimi, and Papa) and friends (especially Mike and Kelsey) have also given me support that has enabled me to achieve this level of education. The path to get to where I am today has been rocky. I have put you all through a lot throughout my life. I appreciate the love you have given me on my brightest and darkest days. You have helped me remember my roots, as well as discover who I can and want to be. Thank you.

I lacked direction during the majority of my undergraduate studies. Two mentors, Ann Bettencourt and Ines Segert, saw something in me. They picked me up and helped me find my passion, and a path to pursue it. I would not have thought graduate school was an option for me without your encouragement. Thank you both for being such 
dedicated professors, and such wonderful people. I strive to be an academic that impacts the lives of students in the same way you have impacted mine.

My graduate mentor, Laura King, has given me a priceless gift. Laura has provided me with an example not only of excellent scholarship, but also a model of how to be a deeply kind and compassionate human being. Her passion for life and for science is inspiring. She has poured unmeasurable time, thought, and effort into helping me grow into the scholar and the person I am today. She has taught me the value of things that before I did not know how to value. With her guidance, my ability to think, to understand human life, and to see beauty in the world have blossomed into something I could not have imagined 6 years ago. The only way I can truly thank you is with my commitment to spreading this gift to others as I continue my journey.

Finally, I would like to thank the remaining members of my committee, Jamie Arndt, Amanda Rose, and Rebecca Scott, for dedicating their time, intellect, and energy to my dissertation proposal and defense during an unprecedented global pandemic. 


\section{TABLE OF CONTENTS}

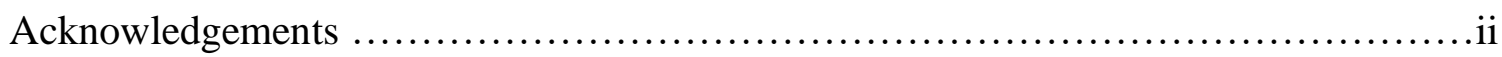

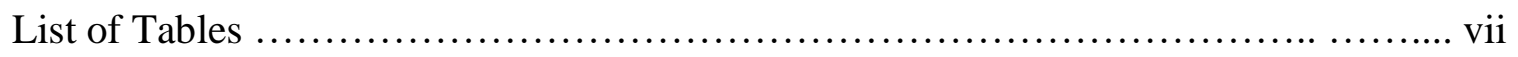

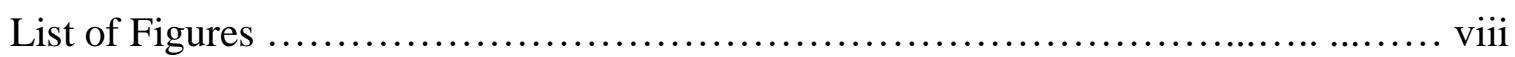

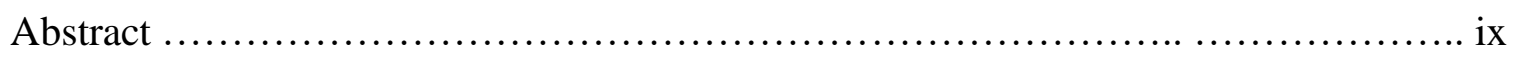

Chapter 1 ............................................................... 1

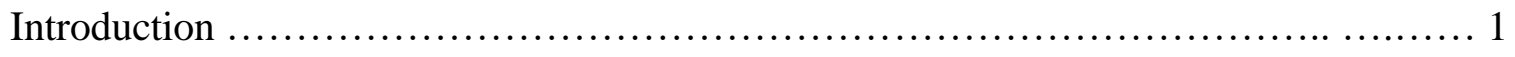

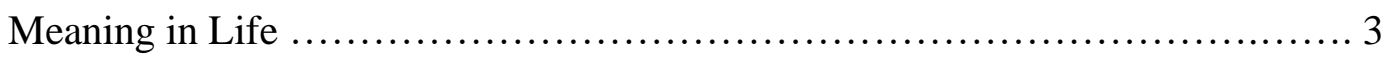

Uncertainty and the Existential Function of Ideology ....................... 5

Meaning in Life, Religious Group Heterogeneity, and Religious Inclusivity...... 8

Diversity, Inclusivity, and American Identity............................ 10

Rhetorical Style .................................................. 13

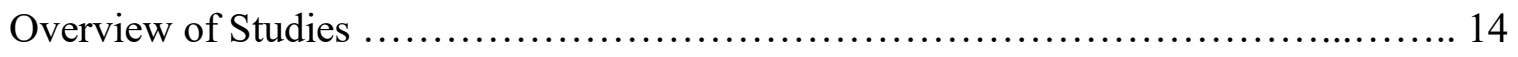

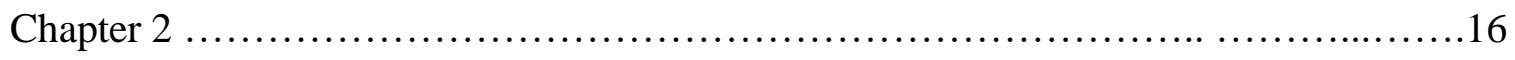

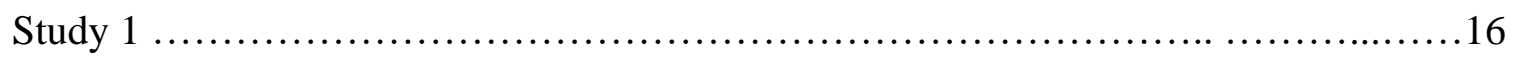

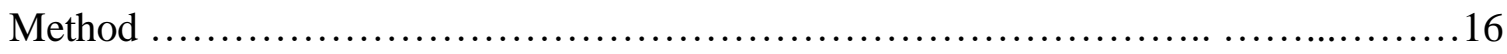

Inclusive / Exclusive ............................................. 17

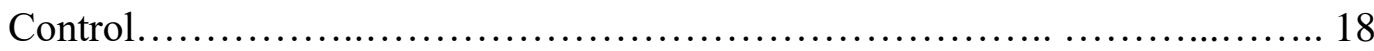

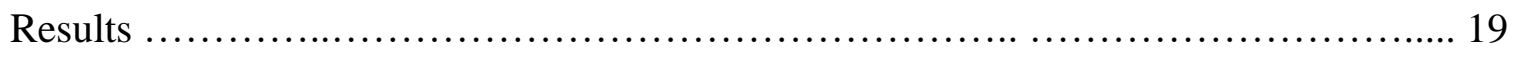

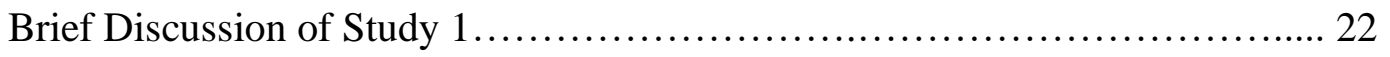

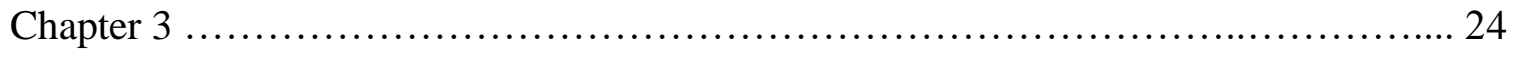

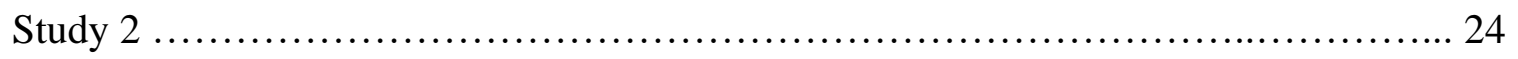

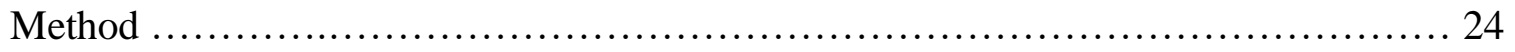




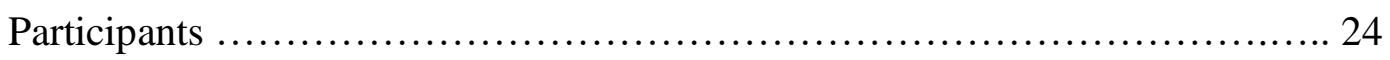

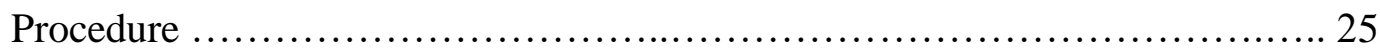

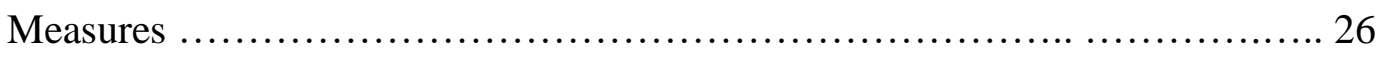

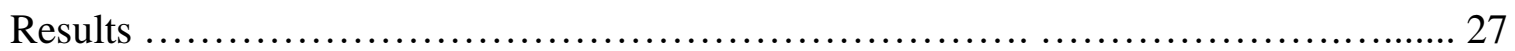

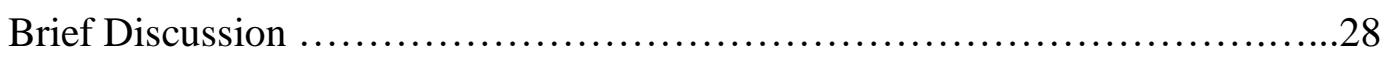

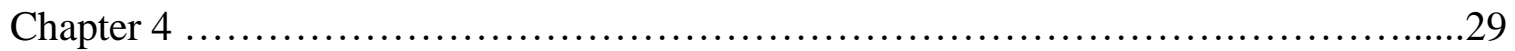

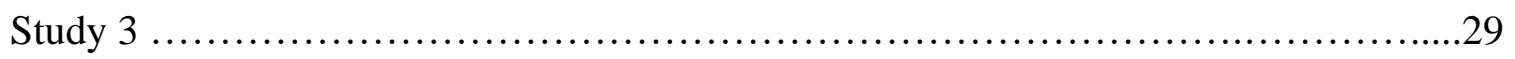

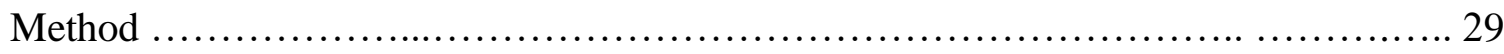

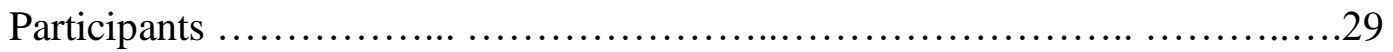

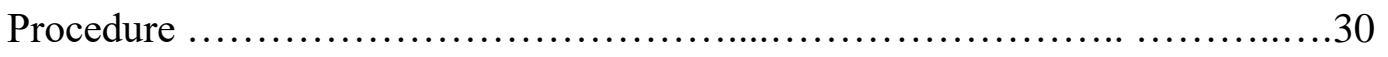

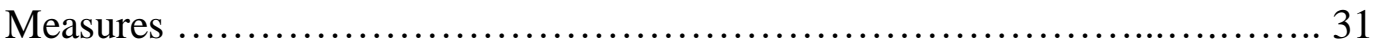

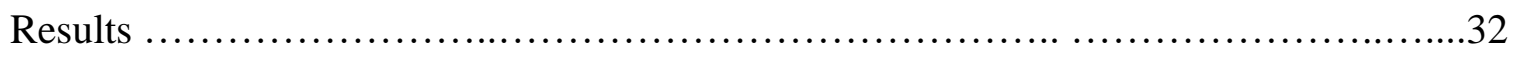

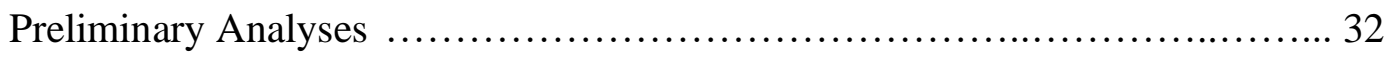

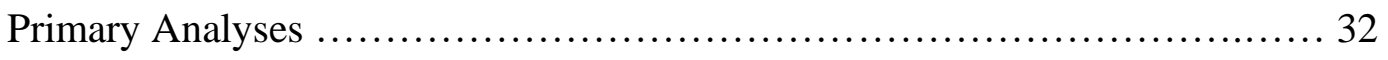

Sensitivity Power Analysis............................................33

Assessing Support for the Null......................................34

Mini-Meta Analysis....................................................

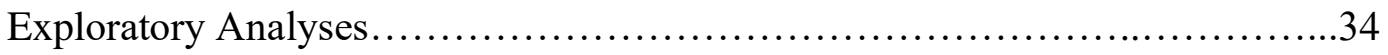

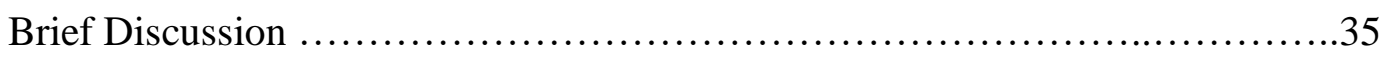

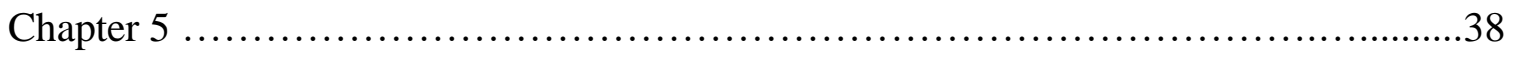

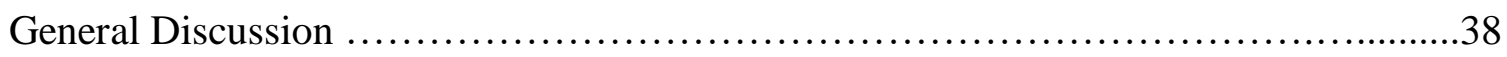

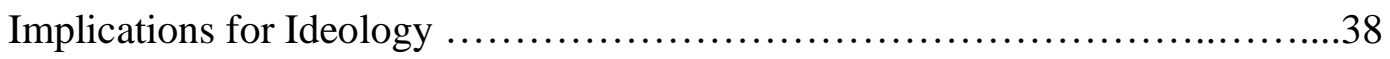

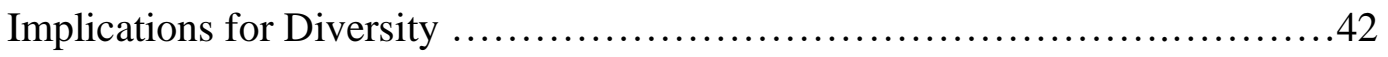




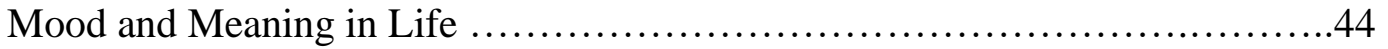

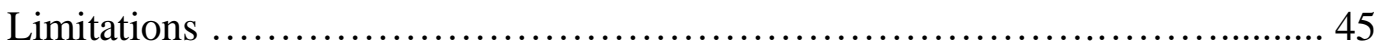

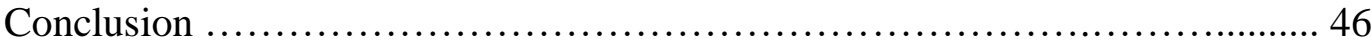

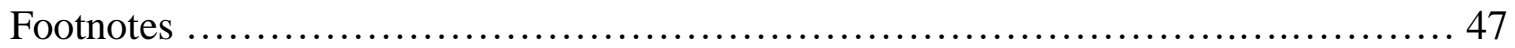

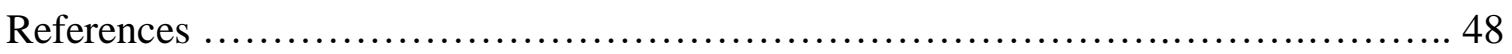

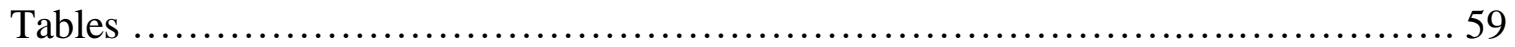

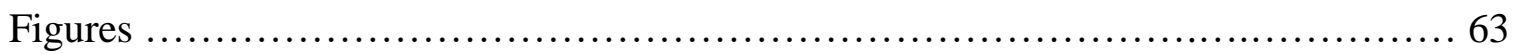

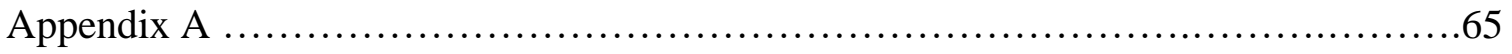

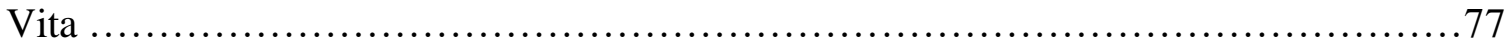




\section{List of Tables}

Table

Page

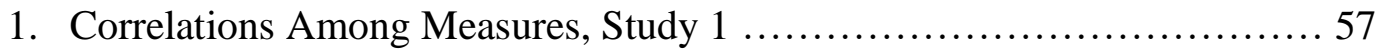

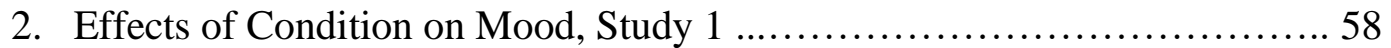

3. Correlations Among Measures, Study 2 ............................. 59

4. Correlations Among Measures, Study 3 .............................. 60 


\section{List of Figures}

Figure

Page

1. Mediation of the Effect of Condition by Facets of Meaning, Study 1........61

2. Mediation of Condition Effect on Global Meaning by Uncertainty, Study 2..62 


\begin{abstract}
Diversity and representation are among the most pressing issues facing the modern world. Communications designed to promote diversity involve numerous dimensions. Here, I focused on two separable dimensions: What is conveyed by a message (inclusive vs. exclusive messaging), and how that message is expressed (pluralistic vs. non-pluralistic rhetoric). Inclusive messages and pluralistic rhetoric emphasize the validity of many different solutions to life's challenges. Exclusive messaging and non-pluralistic rhetoric instead convey one valid answer. I tested whether non-pluralistic rhetorical style (vs. pluralistic rhetorical style) can be leveraged to buffer the existential threat posed by inclusive (vs. exclusive) message content. Study 1 $(N=1,581)$ showed that exposure to inclusive messaging about what it means to be American led to lower meaning in life than exclusive messaging, or a control passage. Study $2(N=1,218)$ showed that conveying an inclusive message about American identity using non-pluralistic rhetoric buffered this existential threat, leading to higher meaning in life than pluralistic expressions of inclusive ideals. Non-pluralistic rhetoric also enhanced certainty, and certainty mediated the effect of non-pluralistic (vs. pluralistic) rhetoric on meaning in life. Study $3(N=556)$ sought to conceptually replicate these patterns in the context of university identity. Implications and future direction for the science of ideology, well-being, and diversity, are discussed.
\end{abstract}




\section{Chapter 1}

\section{Leveraging Rhetorical Style to Reduce the Existential Threat of Inclusive Messaging}

"The liberal call for diversity (and, by extension, pluralism) is ... a call to treat different values equally - to avoid elevating one over other in terms of status and respect. This applies even to conservatism. On some abstract level, liberals feel compelled to proclaim that conservative institutions are equally acceptable, equally valuable, and equally valid in their own intuitions. At the same time, when it comes to the specific content of conservative opinions ... liberals are convinced that conservatives are dead wrong..... Liberals, therefore, face a special conflict that they are especially ill-equipped to resolve: between tolerance and the "tolerance of intolerance."

Jost and Hunyday, 2018

Recently, U.S. society has experienced a renewed push to enhance diversity and representation broadly, and within government, industry, and academia. These efforts are often conveyed using communications that emphasize the value of respect for many different people. In the present research, I focus on two dimensions of such communications: What is expressed by the statement (inclusive vs. exclusive messaging), and how it is expressed (pluralistic vs. non-pluralistic rhetorical style). Although these labels (inclusive/pluralist vs. exclusive/non-pluralist) refer to the same concepts, I use them separately to distinguish between content of messaging and the rhetorical style used to express it. Inclusive messaging and pluralistic rhetoric convey openness to the coexistence of multiple groups, belief systems, or ways of living. In contrast, exclusive messaging and non-pluralistic rhetoric convey the existence of only one valid way to approach life and to solve complex problems.

Inclusive and pluralistic ideals are fundamental to American life, reflected in the founding documents of our country (e.g., all people are created equal), and cultural perceptions (e.g., America as a cultural melting pot or cultural mosaic) (Lipset, 1996). Yet, diversity efforts are often met with resistance. For instance, individuals differ in the 
extent to which they endorse inclusive and pluralistic ideals (Sidanius, Pratto, Bobo, 1996; Devos \& Banaji, 2005; Duckitt, 2001). Diversity movements, such as Black Lives Matter, are often met by counter movements, such as All Lives Matter. Leaders of such movements are also polarizing. Martin Luther King Jr., widely viewed as an American hero today, was evaluated negatively by $63 \%$ of Americans in 1966 (according to Gallup, Edwards-Levy, 2018). Pushback is a common response to communications about diversity that not only manifests among everyday Americans, but also among scientists, a group for whom underrepresentation remains acute. Recent movements to enhance racial, gender, and sexual representation in psychology have been countered in numerous ways including publications disputing the severity of microaggressions (Haslam et al., 2020; Lilienfeld, 2017), competing calls for viewpoint diversity (Hagaa, 2020; Honeycutt \& Jussim, 2020; Winegard \& Clark, 2020; which may fundamentally be at odds with other forms of representation), and magnifying potential restrictions to academic freedom resulting from "cancel culture" (Kauffman, 2021).

Why might inclusive messaging and pluralistic rhetoric, which are intended to advance goals that are foundational to U.S. society, fail to attract broad appeal? Existential concerns may to central to understanding these phenomena. Specifically, inclusive messaging characterizes the world in ambiguous terms that may be relatively difficult to grapple with: That all views can be valid and warrant respect. Exposure to these likely produces aversive psychological experiences. Because they highlight nuance, relativism, and the value of heterogenous groups, I expect that inclusive messages render the world less comprehendible, threatening the experience of meaning in life. Importantly, it may be possible to express any message using a variety of rhetorical 
styles. In the current studies, I tested whether the way a message is expressed (pluralistic vs. non-pluralistic rhetoric) can be leveraged to buffer the existential threat posed by what the message conveys (inclusivity vs. exclusivity). It may be possible to reduce the negative existential effects of inclusive messaging by expressing these ideas with a nonpluralistic style, conveying that inclusivity is the only valid solution to modern problems (e.g., intolerance of intolerance).

Three studies tested these hypotheses. Study 1 tested whether exposure to inclusive messaging about what it means to be American (i.e., there are many valid ways to be American) leads to lower meaning in life, relative to exclusive (i.e., there is only one right way to be American) or a control message. Studies 2 (American identity) and 3 (university identity) tested whether one way to counteract the existential threat of inclusive message content is to convey these ideas using non-pluralistic rhetoric (that inclusivity is the one and only way to solve our modern challenges). I also tested whether the effect of non-pluralistic (vs. pluralistic) rhetoric was explained by changes in uncertainty. Before presenting the studies testing these predictions, I further explain the rationale behind them.

\section{Meaning in Life}

Meaning in life is an important aspect of well-being. Meaning in life is often studied as an individual difference, and indeed it is relatively stable over time (Krause \& Hayward, 2014; Costin \& Vignoles, 2019). However, research also shows that meaning in life can fluctuate within days (Tov \& Lee, 2016), and in the context of experimental paradigms (e.g., King et al., 2006). The experience of meaning in life is often viewed as a eudaimonic type of well-being. In turn, it is perceived (inaccurately) by everyday people 
(Phillips, De Freitas, Mott, \& Knobe, 2017) and scientists (see Kashdan, Biswas-Diener, \& King, 2008; Ward \& King, 2016) alike as a rare experience reserved for intellectual and moral elites in society. In contrast, meaning in life is a subjective evaluation that can be conceptualized as a feeling (Heintzelman \& King, 2014). For instance, building on the model of mood-as-information (Schwarz \& Clore, 2003), the meaning as information approach (Heintzelman \& King, 2014) argues that the feeling of meaning in life functions to convey information to the individual about the extent to which one's experiences and the world around them are making sense. Although profound and virtuous experiences certainly contribute to higher meaning in life (e.g, Ryff, 2018; Rivera, Vess, Hicks \& Routledge, 2019), so do every day experiences, such as relying on intuition (Heintzelman \& King, 2016), or engaging in daily routine (Heintzelman \& King, 2019). In fact, simply being in a positive mood is a robust predictor of meaning in life (King et al., 2006). Daily positive mood more strongly predicts meaning in life than goal progress (King et al., 2006). Overall, contemporary science conceptualizes meaning in life is an adaptive aspect of human experience, and as such, most people experience their lives as pretty meaningful (King \& Hicks, 2021).

The global experience of meaning in life arises from at least three lower-order facets (e.g., George \& Park, 2016; Costin \& Vignoles, 2019). The first, existential significance, refers to the perception that one's life matters to important others, and to society generally, and that one's contributions have an impact on the world. Purpose is the second facet, which reflects the feeling that one's life is directed by the pursuit of valued goals. The third facet, coherence, is the perception that one's experiences fit together and comprise a unified whole. Each of these facets contribute to the global 
experience of meaning in life (see Krause \& Hayward, 2014). For instance, experiences that contribute to existential significance, including social relatedness, and reminders of social relationships causally enhance meaning in life (Hicks \& King, 2009). For purpose, daily goal progress positively predicts perceptions of meaning in life (King, Hicks, Krull, \& Del Gaiso, 2006). Manipulations that lead people to view the world with greater coherence, such as the patterned presentation of stimuli (Heintzelman, Trent, \& King, 2013), and exposure to processing fluency (Trent, Lavelock, \& King, 2013) boost meaning in life.

Conceptually, inclusivity and pluralism impinge on all three facets of meaning. As they place a person's beliefs in the context of other, equally valuable beliefs, they may threaten the idea that these beliefs are special or important, impinging on existential significance. Placing one's cherished goals in a context of innumerable other equally valid goals may lower purpose. Finally, as they avow respect for many different right answers, pluralistic views may call into question the very meaning of the word "right." To the extent that pluralistic perspectives characterize the world in a way that is more difficult to understand, they may threaten a sense of meaning in life (see Heintzelman \& King, 2014).

\section{Uncertainty and The Existential Function of Ideology}

The potential relevance of inclusive messaging and pluralistic rhetoric to existential meaning is also supported by research on ideology, meaning in life, and uncertainty. Conservatism is commonly defined along two dimensions: Preference for the status quo, and opposition to equality. Those who endorse conservatism report higher well-being (Napier \& Jost, 2008), including life satisfaction (Onreat, Van Hiel, \& Dhont, 
2013), positive mood, and meaning in life (Newman et al., 2019). Meaning in life appears to be most central to this association. For instance, controlling for meaning in life wipes out the relationship between conservatism (Newman et al., 2019) and right-wing authoritarianism (Womick et al., 2019) and life-satisfaction.

Liberalism is defined as openness to social change, and support for equality (Jost et al., 2003). As reflected in the opening quote, liberalism is thus egalitarian, inclusive, and pluralistic (e.g., the valuing of equal rights for all races, genders, and sexual orientations). Little research has sought to understand why left-wing views fail to promote perceptions of life's meaning. Egalitarian views carry a positive message--that everyone can be a valuable, contributing member of society, and that all views warrant respect. Why should such a positive idea not promote a sense of meaningfulness? One reason may be that liberal views are often expressed using pluralistic rhetorical style, and conservative views tend to be expressed using non-pluralistic rhetorical style (Schoor, 2017). To the extent that liberal views and the expression of them implicate inclusivity and pluralism, they may characterize the world in ambiguous and uncertain terms.

The Theory of Conservatism as Motivated Social Cognition argues that one of the reasons people adopt right-wing ideologies is because they serve an epistemic need to reduce uncertainty (Jost, Glaser, Kruglanski, \& Sulloway, 2003). Research supports this theory. For instance, conservative ideology is predicted by constructs reflecting epistemological aversion to uncertainty, such as personal need for structure, (Altemeyer, 1998), ambiguity intolerance (e.g., Jessani \& Harris, 2018), low integrative complexity (Tetlock, 1983), need for cognitive closure (Kruglanski \& Webster, 1996), and cognitive rigidity (Choma et al., 2014). Thus, conservative beliefs may function to fill cognitive 
deficits for people that are pre-disposed to experience aversion to uncertainty ${ }^{1}$. According to Uncertainty Identity Theory (Hogg, 2007), one outcome resulting from this uncertainty-reducing function may be that right-wing views contribute to meaning in life, although this possibility has not been empirically tested.

Existing literature on ideology and well-being is limited in numerous ways. For instance, the reasons why conservatives report higher and liberals report lower well-being and meaning in life remain controversial (see Napier \& Jost, 2008; Schlenker et al., 2012). Ambiguity surrounding these relationships may result from numerous sources. First, previous approaches have largely focused on understanding the relationship between conservatism and life satisfaction, which is considerably weaker than the relationship between conservatism and meaning in life (Newman et al., 2019). Second, past research has failed to adopt experimental approaches to testing features of ideology that might causally influence meaning in life. Likewise, in contrast to the present research, prior studies have focused solely on examining the relationship between the content of ideology and well-being (e.g., inclusive vs. exclusive values), rather than focusing also on the way in which beliefs are expressed (i.e., rhetorical pluralism vs. nonpluralism). Finally, almost all previous research on ideology and well-being has focused on understanding the nature of conservatism, how to best define and measure the construct, and why conservatives are happier, rather than focusing on the nature of liberal views and why these may threaten the experience of meaning.

Certainly, liberal views are associated with positive outcomes, such as openness (Carney, Jost, Gosling \& Potter, 2008), empathy (Hasson, Tamir, Brahms, Cohrs, \& Halperin, 2018), compassion (Hirsh, DeYoung, Xu, \& Peterson, 2010), and support for 
policies and movements that reduce inequality (Choma et al., 2020), but well-being is not among them. The research and theory reviewed above suggests that because left-wing views are fundamentally more inclusive, they are less poised to boost meaning in life by reducing perceptions of uncertainty. Instead, inclusivity and pluralism may threaten meaning in life because they characterize the world with a high level of nuance, ambiguity, and relativism. Thus, the proposed studies will measure uncertainty as a potential mediator of the effect of pluralistic rhetoric on meaning in life.

\section{Meaning in Life, Religious Group Heterogeneity, and Religious Inclusivity}

Support for the proposed effect of inclusive vs. exclusive messaging and

pluralistic vs. non-pluralistic rhetoric comes from existing research on the relationships between meaning in life and religiosity, religious groups, and religious messaging. The contribution of religiosity to meaning in life is well documented (Dar \& Iqbal, 2019; Steger \& Frazier, 2005; You \& Lim, 2019). However, both the nature of religious groups and religious messaging serve existential meaning functions above and beyond religiosity.

First, Zhang and colleagues (2018) reported two studies in which they randomly assigned participants to read descriptions of religious groups with homogenous (corresponding to exclusivity) or heterogeneous (corresponding to inclusivity) beliefs. They found that reading about heterogeneous religious groups led to lower meaning in life than reading about homogenous religious groups. These results provide initial evidence for the existential threat posed by inclusivity. Inclusivity may threaten meaning because it may render perceptions of the groups to which one belongs less clearly defined, and less cohesive, ultimately reducing certainty (e.g., Hogg, 2007). 
Second, a recent series of studies showed that exposure to inclusive messaging about what it means to be Christian (i.e., that there are many valid ways to be Christian) led to lower meaning in life than exposure to exclusive messaging about Christian identity (i.e., that there is only one right way to be Christian), and control messaging (Womick et al., under review). Clearly, these ideas hold direct relevance to the conceptualization of America as a cultural mosaic, implicating religious diversity. Yet, despite their prosocial connotations, inclusive characterizations of Christianity threaten the experience of meaning in life. This same pattern was also demonstrated for messaging about what it means to be Muslim, suggesting that the existential threat of inclusivity is not specific to culturally dominant values (at least for U.S. culture). Additionally, uncertainty mediated the effect of inclusive messaging about religious identity on meaning in life. Specifically, inclusive messages about religion enhanced uncertainty about the self, which in turn produced lower perceptions of life's meaningfulness. The present studies examine whether uncertainty serves a similar mediational role for pluralistic rhetoric.

These previous studies constitute compelling indirect evidence for the prediction that inclusive messaging about American identity will threaten certainty and the experience of meaning. However, among ideological belief systems, religion may hold a special relationship with meaning in life. Specifically, religious views not only offer answers to the question of meaning in life, but also to the larger question of the Meaning of Life (King \& Hicks, 2021). Within the framework of Terror Management Theory (Pyszczynski, et al., 2004), endorsing secular or religious beliefs functions to reduce the existential terror resulting from awareness of mortality. However, secular views can only 
offer symbolic immortality. Religious views offer literal immortality. Thus, the existential benefits of religious views may be more potent than their secular counterparts.

These considerations leave open the question of whether exposure to inclusive vs. exclusive messaging about secular topics would affect meaning in life. A recent series of studies showed that, in the absence of religious views, mortality salience causes Americans to increase the duration for which they expect U.S. culture to persist after their death (offering symbolic immortality) (Scott, Schimel, \& Sharp, 2021). This effect does not occur among those who are religious because they already experience the existential comfort afforded by literal immortality. These findings lend credence to the possibility that inclusive vs. exclusive messaging about secular topics hold relevance to existential meaning, as I test here in the context of American (Studies 1 and 2) and university identity (Study 3).

\section{Diversity, Inclusivity, and American Identity}

A vast body of literature on diversity also indirectly supports the relevance of inclusive messaging and pluralistic rhetoric to existential concerns. Cultural and ethnic diversity are an instantiation of inclusivity in the real world, characterized by the presence of different groups of people who endorse different worldviews and take different approaches to life's challenges. White people react negatively to perceptions of increasing racial diversity. After reading information about demographic changes in the U.S., White people tend to believe they will have less power, lower group status, and will become targets of discrimination (Craig \& Richeson, 2017; See Craig, Rucker, \& Richeson, 2018, for a review). Similar negative reactions have been documented among members of various high-status groups towards members of a range of marginalized 
groups and these tend to be motivated by zero-sum beliefs (Wilkins et al., 2015; Wilkins et al., 2017).

This area of research also supports the proposed overlap between conservative beliefs, exclusivity, and non-pluralism. For instance, a recent review of the literature suggests that rather than leading to shifts in attitudes, exposure to diversity simply aggravates existing negative intergroup attitudes among those who endorse right-wing views (see Van Assche, Roets, Van Hiel, \& Dhont, 2019). Building on these findings, Sengupta, Osborne, and Sibley (2019) showed that feelings of group-based relative deprivation (which often result from zero-sum beliefs and perceptions of increasing diversity) contribute to nationalistic ideology, which in turn, predicts higher subjective well-being. Further, experimental research shows that exposure to diversity information causes people to endorse more conservative ideology (Craig \& Richeson, 2014), and promotes group-based conventionalism (Dieckmann, Steffens, \& Methener, 2018; often implicated in right-wing views, Feldman, 2003).

Although issues surrounding diversity and inclusion are salient today, they are not novel. In part, the persistence of these issues is driven by belief in the myth of racial progress (Richeson, 2020; Kraus et al., 2019). Considering historical trends, one could correctly argue that inclusive, pluralistic ideals are no more characteristic of American society than is the reality of our exclusive, non-pluralistic present and past. Resistance to diversity and perpetuation of inequality may be deeply rooted in perceptions of the self and culture. One of the barriers to garnering support for diversity initiatives may be that White, heterosexual, and male categories are often perceived as cultural defaults (DiAngelo, 2018; Bailey \& LaFrance, 2017; Hegarty, 2017; see also the exemplar-based 
model of social judgement, Smith \& Zarate, 1992). Perceptions of cultural defaults not only emerge among everyday Americans (Hegarty, 2017), but also characterize scientists who study sexuality differences (who focus explanations for group differences on lesbian women and gay men more than heterosexuals, Hegarty \& Pratto, 2004); race differences (focusing explanations on Black Americans more than White Americans, Pratto, Hegarty, \& Korchmaros, 2007); and gender differences (focusing explanations more on women than men, Hegarty, 2006). Most importantly for the present purposes, such patterns also extend to perceptions of what it means to be an American. People associate White groups with the category "American" more strongly than African or Asian American groups (Devos \& Banaji, 2005; Cheryan \& Monin, 2005). This pattern of identity denial is especially strong among White Americans who strongly identify with American nationality (Devos \& Banaji, 2005).

Clearly, as a pluralist society that explicitly embraces egalitarian ideals, and as a field that seeks to produce a society and academia that is characterized by greater inclusivity, the findings outlined above present challenges to diversity efforts. Taken together, they point to the possibility that people tend to believe there is one right way to be an American, and that is to be White, heterosexual, and male. These fundamental assumptions about the world and what it means to be American likely play a role in existential meaning, particularly by helping people make sense of their environment, what to expect from it, and to identify their place in it. If inclusive messaging violates these basic assumptions, then it is likely to reduce perceptions of life's meaningfulness. In order to enhance representation, dialogue needs to (and often does) focus on changing perceptions of what can constitute a good American, or a good scientist. These 
communications necessitate inclusive messaging. Here, I propose that one reason people are often resistant to such messages, and diversity movements more broadly, is because they enhance uncertainty about the self, and in turn threaten perceptions of life's meaningfulness. Importantly, although diversity communications necessitate inclusive messaging, it may be possible to express these using a variety of rhetorical styles. Perhaps leveraging different rhetorical styles used to convey inclusive messages can enhance their existential appeal, a possibility I turn to next.

\section{Rhetorical Style}

Because inclusive ideals can have positive consequences for people and society, an important goal for science is to understand how to boost the existential appeal of inclusivity. In the present studies, I consider two dimensions of rhetorical style: Pluralistic rhetorical style conveys openness to the validity of other viewpoints; and Nonpluralistic rhetorical style conveys that one's position is the only valid viewpoint. Inclusive messages tend to be expressed using a pluralistic rhetorical style. For instance, Schoor (2017) analyzed the rhetorical style of candidates in the 2016 Presidential Election, and found that Donald Trump presented a populist rhetorical style, and Bernie Sanders expressed a more pluralistic style.

Despite these naturally occurring associations, it may be possible to convey any ideology pluralistically or non-pluralistically. Indeed, in the real world, some of the most successful egalitarian leaders, such as Martin Luther King Jr. and Eleanor Roosevelt, often took a non-pluralistic rhetorical approach to communicating their inclusive visions. Consider the following excerpt from a speech given by Martin Luther King Jr. (1965): 
"We must all learn to live together as brothers or we will all perish together as fools. This is the challenge of the hour. No individual can live alone, no nation can live alone. Somehow we are interdependent... all life is interrelated. And, we are caught in an inescapable network of mutuality, tied in a single garment of destiny - whatever affects one directly, affects all indirectly."

As evidenced in this passage, the message he conveys is fundamentally inclusive (i.e., everybody is equal and interdependent) but he communicates this message using non-pluralistic rhetoric (i.e., peaceful coexistence is the only solution). Thus, it is possible that one way to reduce the existential threat of inclusive messaging is to convey them in a non-pluralistic way. Popper (1945) took a similar approach in describing the paradox of tolerance, arguing for the necessity of intolerance of intolerant people.

I expect that because the content of inclusive views are fundamentally nuanced and complex, they are less poised to facilitate certainty and meaning in life than views that are exclusive and control messaging. However, it may be that expressing inclusive beliefs using non-pluralistic rhetoric (for instance, that tolerance is the only right answer) reduces their negative impact on uncertainty and the experience of meaning. Thus, Studies 2 and 3 will test the prediction that, compared to pluralistic rhetoric, a nonpluralistic expression of inclusivity will eliminate the negative effect of inclusive messaging on certainty and meaning in life.

\section{Overview of Studies}

Three studies tested the predictions outlined above. In Study 1, I tested whether exposure to inclusive messaging about what it means to be American would lead to lower meaning in life, relative to exclusive or control messaging. In Study 2, I tested whether 
leveraging rhetorical style offers one route by which to reduce the existential threat of inclusive messaging. All participants were exposed to an inclusive message about what it means to be an American, but this message was either conveyed using pluralistic or nonpluralistic rhetorical style. I expected non-pluralistic rhetorical style to boost meaning, relative to pluralistic rhetorical style, effectively eliminating the existential threat of inclusivity. Further, I tested whether uncertainty mediated the effect of condition on meaning in life. Study 3 was designed to conceptually replicate Study 2, instead focusing on what it means to be a university student. 


\section{Chapter 2}

\section{Study 1}

Study 1 tested the prediction that exposure to an inclusive message would lead to lower meaning in life in the domain of American identity. Participants were randomly assigned to read inclusive or exclusive messages about what it means to be American, or a control passage. I expected that inclusive messages would lead to better mood, but controlling for mood, would lead to lower meaning in life than control and exclusive passages. Extending on previous research (Womick et al., under review), I also measured the facets of meaning in life (existential significance, purpose, and coherence), allowing us to test whether the existential threat of inclusivity differed across facets and whether the facets explained the condition effect on global meaning in life.

\section{Method}

I recruited 1,581 participants from Amazon MTurk. Age, $M(S D)=37.64(12.49)$ ranged from 18 to 82 . Participants were 60/7\% women, $72.4 \%$ White/European American, 9.2\% Black/African American, 6.4\% Hispanic/Latinx, 7.8\% Asian, 1.0\% Native American, and 3.3\% indicated “other." Median income was \$50,001-\$75,000. Modal education was a Bachelors.

Participants were first presented with instructions, presented below:

"We are interested in the ways people perceive and remember information about another person. You will be seeing a response to a question given by someone in a previous study. This person was asked to complete a brief writing task and we are going to show you the response that was given. 
While reading, try to suspend judgment and just learn about this person's experience. Try to focus on the ideas conveyed without immediately judging the author. Please pay close attention because later we will be testing your memory of the information communicated.

Now we will show you the question we asked this participant, as well as their response."

After reading instructions, participants were randomly assigned to read an exclusive message about American identity $(n=543)$, an inclusive statement about American identity $(n=541)$, or a control statement $(n=542)$. The passages are shown below, with verbiage from the pluralist condition shown in bold, and the non-pluralist condition shown in italics.

\section{Inclusive/Exclusive}

"To be an American is to love the United States and be proud that you live in one of the greatest countries in the world. Americans are patriots. Sometimes that means fighting against discrimination of other people / self-sacrificing for the common good. It always means building a better future and questioning the justness of the laws of set forth by the constitution / respecting authorities and following the laws of this country that were set forth by the constitution. True Americans get behind an open-minded leader that will listen to constituents and reinvent our American traditions and institutions when needed / strong leader that will protect those laws, and preserve our American traditions and institutions. 
Most importantly, to be American means people with different backgrounds and beliefs coming together and learning from each other to build something better / like-minded people coming together and agreeing to believe in something. It means bettering our culture by educating ourselves, learning from people of other cultures, preserving human dignity, and fighting for the freedom and rights of all human beings / protecting those beliefs from external threats, no matter the costs that may require, be it international conflict or the sacrifice of some liberties by some people in order to preserve the greater good. These things make Americans who they are, some of the / the greatest people on Earth. To me, that's what it means to be an American I If you can't get on board with that, you don't deserve to be here."

\section{Control}

"America's GDP is 18.6 trillion dollars, according to a 2016 report. The U.S. GDP shows an annual rate of change of $1.6 \%$. The U.S. population is 323.4 million. That means the GDP per capita is $57,466.79$ USD. The primary industries contributing to the United States economy are natural resources, such as oil and gas, as well as manufacturing. However, internationally, the United States is known for technological innovation. Currently, energy, transportation, and telecommunications also constitute substantial sectors of the American economy.

It is thought that in the future, more people will be employed in the service industry than in manufacturing in America. The United States military, and the American defense industry also have sizable contributions to the U.S. economy. For instance, there are approximately 1.3 million active personnel 
enlisted in the military, and another 800,000 reserves. The U.S. military budget last year was 610 billion USD."

After reading one of the passages, participants responded to a number of questionnaires. All responses were provided on a scale from 1 (not at all / strongly disagree) to 7 (very much / strongly agree). All items from each scale (all studies) are presented in Appendix A. Participants first completed measures of meaning in life, including the 5-item Presence of Meaning in Life Questionnaire (Steger, Frazier, Oishi, $\&$ Kaller, 2006), $M(S D)=4.95(1.39), \alpha=.92$, and Tripartite Meaning Scale (Costin \& Vignoles, 2019), which measures global meaning in life, $M(S D)=5.26(1.34), \alpha=.82$, existential significance, $M(S D)=4.94(1.45), \alpha=.85$, purpose, $M(S D)=5.14(1.23), \alpha=.80$, and coherence, $M(S D)=5.01(1.27), \alpha=.82$.

After, participants completed face-valid mood descriptors for positive affect, $M(S D)=3.45(1.89), \alpha=.95$, and negative affect, $M(S D)=2.23(1.47), \alpha=.92$. They also rated their agreement with the passage by rating the item, "I agreed with the writer's beliefs in the essay," $M(S D)=4.67(1.47)$. Participants also completed a number of measures outside the central focus of this paper (see Appendix A).

\section{Results}

Correlations among measures are shown in Table 1. Global meaning in life and the facets of meaning were positively related to each other. These were all positively related to positive affect, and negatively associated with negative affect.

Table 2 shows results for condition effects on mood. The inclusive passage led to significantly higher positive affect (both $p$ 's $<.001$ ) and lower NA than the exclusive $(p<.001)$ and control conditions $(p=.025)$. Inclusivity also led to significantly higher 
agreement, $M(S D)=4.87(1.61)$, than the exclusive condition, $M(S D)=3.90(1.35)$, but did not differ from control, $M(S D)=4.94(1.35), F(2,1570)=85.13, p<.001, d=0.66$.

To test condition effects on meaning in life, I created an aggregate of the global meaning in life measures (the TMS global scale and the MLQ-P, $r=.81, p<.001$ ). Reading an inclusive perspective on American identity led to lower meaning in life, $M(S D)=4.93(1.33)$, than the exclusive, $M(S D)=5.22(1.24)$, and control passages, $M(S D)=5.19(1.34)$, both $p$ 's $<.001, F(2,1576)=8.83, p<.001, d=0.21$. Controlling for agreement did not weaken the effect of condition on meaning in life, $F(2,1569)=7.03$, $p=.001, d=0.20$.

I next tested whether the existential threat of inclusive messaging varied across the facets of meaning in life. A repeated measures GLM, treating PA and NA as covariates, facets of meaning as a within person factor (with 3 levels), and condition as a between participants factor showed no condition $\mathrm{X}$ facets interaction, $F(4,1571)=1.16$, $p=.33$. Thus, the effect of condition was not especially strong for any particular facet of meaning. Instead, the facets showed patterns similar to global meaning in life. The inclusive condition led to lower existential significance, $M(S D)=4.74(1.49)$, than the exclusive condition, $M(S D)=5.11(1.38), p<.001$, and control condition, $M(S D)=4.99(1.47), p=.005, F(2,1576)=9.61, p<.001, d=0.22$. Likewise, inclusive messaging led to lower purpose, $M(S D)=5.01(1.25)$, than the exclusive condition, 5.25(1.21), $p<.001$, and control condition, $M(S D)=5.16(1.20), p=.038, F(2,1576)=5.90$, $p=.003, d=0.17$. Lastly, the inclusive condition led to significantly lower coherence, $M(S D)=4.86(1.30)$, than the exclusive condition, 5.12(1.22), $p<.001$, and marginally 
lower coherence than the control condition, $M(S D)=5.07(1.29), p=.066, F(2,1576)=7.19$, $p=.001, d=0.19$.

Do changes in the facets of meaning explain the results for general meaning in life? To address this question, I used the aggregate of the two global meaning measures as the outcome. Because the control and exclusive conditions did not differ, I collapsed these and tested for mediation of the differences between the inclusive condition (coded 1) and control/exclusive conditions combined (coded 0). I used PROCESS Macro for SPSS, v22.16.3 (Model 4, Hayes, 2016), entering PA and NA as control variables, condition as the predictor, and existential significance, purpose and coherence as parallel mediators. Without the mediators, the effect of condition on global meaning in life was significant, $B(S E)=-0.31(.07), p<.001$.

As can be seen in Figure 1, all three facets of meaning were affected by condition and combined to fully explain the effect of condition on global meaning in life. The indirect effects of condition through all three facets were significant (none of the bootstrapped 95\% confidence intervals included 0). For existential significance, $0.07(0.02)[-0.11,-0.04]$; for purpose $-0.06(0.02)[-0.10,-0.02]$; and for coherence, $0.11(0.03)[-.17,-.05]$.

Interestingly, following the manipulation, the path from coherence to global meaning in life was significantly stronger than the paths from existential significance $(z=9.39)$ and purpose $(z=5.30), p$ 's $<.001$. Purpose was significantly stronger than existential significance $(z=2.68), p=.003$. Thus, inclusive messaging affects global meaning through all three facets, but the global perception of meaning appears to be most strongly contingent on coherence. 


\section{Brief Discussion of Study 1}

Study 1 showed that although inclusive views about what it means to be an American enhanced mood, they led to lower meaning in life. The effects of the control condition in Study 1 were unexpected (low PA, high meaning in life) but, importantly, as predicted, the inclusive passage led to lower meaning in life relative to the exclusive perspective. Study 1 also showed that the inclusive (vs. exclusive and control) condition affected all three facets of meaning and changes in these facets explained the condition effect on global meaning in life.

Study 2 built on Study 1 results by advancing two important goals. First, the study addressed the key prediction offered previously, that non-pluralistic rhetorical style would buffer the existential threat of inclusive message content. In this study (and Study 3), all participants were exposed to inclusive messages. The manipulation consisted of whether the inclusive message was conveyed using pluralistic vs. non-pluralistic rhetoric (e.g., pluralistic rhetoric $=$ the author conveys inclusive views, but that other people may hold different but valid perspectives; non-pluralistic rhetoric $=$ the author conveys pluralistic views, and that these are the only valid answer to a given problem). In Studies 2 and 3, this manipulation of pluralistic vs. non-pluralistic rhetoric used a single sentence.

The second goal of Study 2 (and 3) was to test a candidate mediator, uncertainty. Past research (Womick \& King, under review) showed that the meaning threat posed by inclusive religious messaging is explained by uncertainty. Here I sought to test whether the effect of pluralistic vs. non-pluralistic rhetoric is similarly explained by uncertainty. Thus, in Studies 2 and 3, I included measures of uncertainty after the manipulation (and 
before measures of meaning in life) to test whether non-pluralistic rhetoric reduces uncertainty, and through reduced uncertainty enhances the experience of meaning in life. 


\section{Chapter 3}

\section{Study 2}

Study 2 represented a first test of my hypothesis that one way to reduce the existential threat of inclusivity is to express these values using non-pluralistic rhetorical style. For this study, I tested this prediction in the context of what it means to be an American. All participants were exposed to an inclusive description of what it means to be an American, and these messages were either conveyed using pluralistic (that inclusivity is just one among many valid ways to think about what it means to be American) or non-pluralistic rhetorical style (that inclusivity is the only right way to view what it means to be American). I excluded a control condition from the design of Study 2 in order to maximize statistical power while reducing resource burden. I expected that conveying inclusive perspectives on American identity using non-pluralistic rhetoric would lead to worse mood, but controlling for mood, would lead to higher meaning in life, and higher certainty. I further expected that uncertainty would mediate the effect of condition on meaning in life. Study 2 was pre-registered, https://osf.io/y4ajz/?view only=43de793c8e73462b9fe012ca65d23e81.

\section{Method}

\section{Participants}

I recruited 1,218 participants from Cloud Research. Age, $M(S D)=37.32(12.45)$ ranged from 18 to 82 . Participants were $54.0 \%$ women, $70.7 \%$ White/European American, 13.0\% Black/African American, 7.7\% Hispanic/Latinx, 4.9\% Asian, 1.2\% Native American, and 2.6\% indicated “other." Median income was $\$ 50,001-\$ 75,000$. Modal education was a Bachelors. 


\section{Procedure}

Participants were first presented with the same instructions as in Study 1.

Following these instructions, participants were randomly assigned to read an inclusive description of American identity either expressed using pluralistic rhetorical style $(n=611)$, or non-pluralistic rhetorical style $(n=601)$. The passages are shown below, with verbiage from the pluralist rhetoric condition shown in bold, and the non-pluralist rhetoric condition shown in italics:

"To be an American is to love the United States and be proud that you live in one of the greatest countries in the world. Americans are patriots. Sometimes that means fighting against discrimination of other people. It always means building a better future and questioning the justness of the laws of set forth by the constitution. True Americans get behind an open-minded leader that will listen to constituents and reinvent our American traditions and institutions when needed.

Most importantly, to be American means people with different backgrounds and beliefs coming together and learning from each other to build something better. It means bettering our culture by educating ourselves, learning from people of other cultures, preserving human dignity, and fighting for the freedom and rights of all human beings. These things make Americans who they are, some of the greatest people on Earth. [I know that's not what everyone thinks it means to be American, and I can appreciate other views, but it is what seems right to me (pluralistic rhetorical version) / If you can't get on board with that, you don't deserve to be here (non-pluralistic rhetorical version)]." 


\section{Measures}

After reading one of the passages, participants completed the following measures in the order presented here. Unless otherwise noted, all responses were provided on a scale from 1 (not at all / strongly disagree) to 7 (very much / strongly agree). Uncertainty was measured using 5 face valid items adapted from The Uncertainty Response ScaleEmotional (Grecco \& Roger, 2007) and the Mishel Uncertainty Illness Scale (Mishel, 1981), $M(S D)=2.72(1.43), \alpha=.92$. To measure global perceptions of life's meaningfulness, I administered the same 5-item Presence of Meaning in Life Questionnaire as in Study $1, M(S D)=4.85(1.35), \alpha=.89$. I also administered the same measures of mood: For PA, $M(S D)=4.07(1.70), \alpha=.93$; and NA, $M(S D)=2.20(1.51)$, $\alpha=.94$.

I additionally measured numerous constructs outside of the scope of the central predictions of this study. Participants evaluated their agreement with the author, $M(S D)=5.22(1.44)$, and the ease of comprehending the passage (using two items: "How easy was it to read the passage?; How easy was it to understand the message?"), $M(S D)=6.03(0.92)$, inter-item $r=.78, p<.001$. I also measured centrality of being American to participant's sense of identity (using a single item, "How important is being an American to your sense of identity, overall?"), $M(S D)=4.94(1.71)$. Other measures are described in Appendix A.

Finally, participants were asked to indicate whether they read the passage (Yes/No). Participants who indicated they did not read the passage were excluded from analyses $(n=56)$. 


\section{Results}

Correlations among measures are shown in Table 3. Meaning in life was negatively related to uncertainty and negative affect, and was positively related to positive affect. Uncertainty was strongly positively correlated with negative affect. Positive and negative affect were unrelated.

As I expected, pluralistic rhetoric led to higher positive affect, $t(1145)=2.73$, $p=.007$ (pluralist rhetoric, $M(S D)=4.19(1.62)$; non-pluralist rhetoric, $M(S D)=3.91(1.46)$ ), but unexpectedly had no effect on negative affect, $p=.82$. Controlling for mood, pluralistic rhetorical style led to lower meaning in life, $M(S D)=4.74(1.35)$, than nonpluralistic rhetorical style, $M(S D)=4.94(1.37), F(1,1142)=6.55, p=.011, d=0.16$ (when not controlling for mood, the effect of condition on meaning in life was non-significant, $p=.10$, but in the expected direction). Condition also had the expected effect on uncertainty. Controlling for mood, pluralistic rhetoric enhanced uncertainty, $M(S D)=2.71(1.38)$, compared to non-pluralistic rhetoric, $M(S D)=2.56(1.36)$, $F(1,1142)=5.92, p=.015, d=0.14$.

Uncertainty also mediated the effect of condition on meaning in life, as shown in Figure 2. I tested for mediation using PROCESS macro for SPSS (Hayes, 2016; model 4), using a dummy coded variable to represent condition ( $0=$ pluralist condition; $1=$ nonpluralist condition). For comparison purposes, without controlling for uncertainty, condition affected meaning in life, $B(S E)=0.19(0.07), p=.009$. Controlling for uncertainty fully explained the condition effect on meaning in life, $B(S E)=0.15(0.07), p=.051$. The indirect effect of condition on meaning in life through uncertainty was significant, 
$0.05(0.02), 95 \% \mathrm{CI}=[0.01,0.10]$. No variables moderated the effect of condition on meaning in life or uncertainty.

\section{Brief Discussion}

Study 2 provided support for the prediction that one way to reduce the existential threat of inclusive messaging is to convey these values using non-pluralistic rhetoric. Thus, perhaps one way to enhance the appeal of inclusive ideals for general audiences is to convey that these approaches are the only valid way to solve real-world challenges. I also found support for the second prediction—one reason that conveying inclusive values using non-pluralistic rhetoric is existentially appealing is because it engenders a greater sense of certainty. It is through boosted certainty that non-pluralistic rhetorical style enhances meaning in life.

Of course, effect sizes in Study 2 were small (again, as expected). However, these effects are notable considering the manipulation simply consisted of a single sentence, and was delivered without impactful cues — such as images, video, audio, and/or the presence of other people — that would typically accompany such messages in the real world. Next, I sought to conceptually replicate these results in another population and in a different domain. 


\section{Chapter 4}

\section{Study 3}

The purpose of Study 3 was to conceptually replicate Study 2. I again tested the prediction that inclusive values conveyed using pluralistic rhetoric would lead to lower meaning in life and higher uncertainty than those same values conveyed using nonpluralistic rhetoric. As in Study 2, I tested the effect of these messages on mood, and tested for mediation by uncertainty. Study 3 built on Study 2 by testing these ideas in a new context, and in a different population: Attitudes about what it means to be a student at Mizzou. Recall that Study 1 tested whether the effect of inclusive messaging had differential relevance to the facets, pointing to the possibility that these may be most relevant to global meaning in life via coherence. In Study 3, I included measures of the facets of meaning in order to probe whether the effect of pluralistic vs. non-pluralistic rhetoric showed a similar pattern. Study 3 was pre-registered (https://osf.io/jvqez/?view_only=da2d4069eaf74ba7af96a04210ebaf8e).

\section{Method}

\section{Participants}

I recruited 556 participants from January 20, 2020 to March 23, 2021, who were introductory psychology students participating in return for partial fulfillment of course requirements. The sample was $61.6 \%$ women, $80.3 \%$ White / European American, $7.2 \%$ Black / African American, 5.6\% Asian / Asian American, and 3.3\% indicated "other." Age, $M(S D)=19.23(2.08)$ ranged from 18 to 49 . 


\section{Procedure}

Study 3 followed the same general procedure as the previous studies. After reading the same instructions, all participants read an inclusive description of what it means to be a Mizzou student. Participants were randomly assigned to read this passage expressed using pluralistic $(n=274)$ or non-pluralistic $(n=282)$ rhetorical style. Full passages are presented below (pluralistic rhetoric presented in bold; non-pluralist presented in italics):

"I love the University of Missouri, Columbia, and I think that's important to being part of the Mizzou community. I'm proud to attend the greatest university in Missouri. Sometimes, being a true Mizzou student means fighting against the discrimination of other people. It always means building a better future and questioning the justness of the rules that govern our classes and campus. True Mizzou students get involved in campus events and give back to the community.

Most importantly, to be a member of the Mizzou community means people with different backgrounds and beliefs coming together and learning from each other to build something better. It means bettering our campus culture by educating ourselves, respecting each other, and fighting for the rights of all human beings. These things make Mizzou students who they are, some of the greatest people on Earth. I know that's not what everyone thinks it means to be a Mizzou student, and I can appreciate other views, but it is what seems right to me (pluralist rhetoric) / If you can't get on board with that, you don't deserve to be here (nonpluralist rhetoric)." 


\section{Measures}

After reading one of these passages, participants completed measures in the following order. Unless otherwise noted, all ratings were given on a scale from 1 (not at all / strongly disagree) to 7 (very much / strongly agree). Participants completed the same measures of uncertainty (although the word "American" was replace with "Mizzou student"), $M(S D)=3.31(1.34), \alpha=.90$; global meaning in life, $M(S D)=3.31(1.34), \alpha=.90$; positive mood, $M(S D)=3.31(1.34), \alpha=.90$; and, negative $\operatorname{mood}, M(S D)=3.31(1.34), \alpha=.90$, as in the previous studies.

Next, participants completed a measure of identity centrality ("How important is being a Mizzou student to your sense of identity overall'), $M(S D)=3.31(1.34)$. At the end of the study, I administered the 15-item Existential Meaning Scale (George \& Park, 2016), which measures the facets of meaning. These include existential significance, $M(S D)=3.31(1.34), \alpha=.90 ;$ purpose $M(S D)=3.31(1.34), \alpha=.90 ;$ and coherence, $M(S D)=3.31(1.34), \alpha=.90$.

Finally, participants completed a number of measured to index inattentive responding. First, participants indicated whether or not they read the passage, either responding "yes" $(n=486)$, or "no" ( $n=69)$. Participants who indicated they did not read the passage were excluded from analyses. Additionally, I embedded two attention checks in the survey. Participants who failed either of these were excluded from analyses $(n=116)$. After making exclusions based on these variables, I was left with a final sample of 396 to test the hypotheses.

Participants also completed a number of additional measures outside the central scope of this paper (see Appendix A). 


\section{Results}

\section{Preliminary Analyses}

I first examined whether participants who completed the study before $(n=182)$ the pandemic systematically differed from those who completed it during the pandemic $(n=214)$. Those who participated during the pandemic reported significantly lower positive affect, $t(394)=2.75, p=.006$ (pre-pandemic PA, $M(S D)=4.18(1.43)$ vs. pandemic PA, $M(S D)=3.78(1.39)$. Participants during the pandemic also experienced their lives as less significant, $M(S D)=4.76(1.29)$ than those who completed the study before the pandemic, $M(S D)=5.04(1.35), \mathrm{t}(294)=2.01, p=.045$. The pandemic did not significantly affect any other variables, all $p$ 's $>.18$.

Correlations among measures are shown in Table 4. Uncertainty was negatively related to global meaning and the facets, which were all positively related to each other. Uncertainty was negatively and meaning variables were positively related to positive affect. Uncertainty was positively associated with negative affect, and negative affect was negatively related to meaning variables. Positive and negative affect were negatively correlated.

Condition had no significant effect on positive or negative affect, agreement, or identity centrality. Unexpectedly, condition significantly affected liberalism, with pluralistic rhetoric leading to higher liberalism $(M(S D)=4.88(0.98))$, than non-pluralistic rhetoric, $(M(S D)=4.61(1.03)), t(394)=2.61, p=.009$.

\section{Primary Analyses}

As predicted, pluralistic rhetoric led to significantly higher uncertainty, $M(S D)=2.88=0(1.09))$, than non-pluralistic rhetoric, $M(S D)=2.62(1.06)), t(394)=2.46$, 
$p=.014$. Failing to support my predictions, condition did not significantly affect meaning in life. However, means were generally in the predicted direction. For global meaning in life and purpose, the magnitude of the difference was smaller than observed in previous studies, and failed to approach statistical significance, both $p$ 's $>.55$ (for global meaning in life, pluralism, $M(S D)=4.96(1.20)$ vs. non-pluralism, $M(S D)=5.02(1.17)$; for purpose, pluralism, $M(S D)=5.77(1.03)$ vs. non-pluralism, $M(S D)=5.79(1.07))$. For comparison, the mean difference between conditions on meaning in life in Study 2 was $0.20(d=0.16)$. Although condition effects on existential significance and coherence did not reach statistical significance in Study 3, $\left(F^{\prime} \mathrm{s}(1,392)=2.90\right.$ and 2.06, $p$ 's $=.09$ and $.15, d$ 's $=$ 0.17 and 0.14 , respectively) the mean difference between conditions on these variables were similar to previous studies: Pluralistic rhetoric led to lower existential significance, $M(S D)=4.78(1.33)$ than non-pluralistic rhetoric, $M(S D)=5.00(1.32)$, mean difference $=$ 0.22; and pluralism led to lower coherence, $M(S D)=5.02(1.21)$ than non-pluralism, $M(S D)=5.17(1.11)$, mean difference $=0.15$.

Sensitivity Power Analysis. Because these patterns were consistent with predictions and observations in previous studies, and because Study 3 had a much smaller sample size than the previous studies, I conducted a post-hoc sensitivity power analysis to examine whether Study 3 was adequately powered to detect significant effects of the magnitudes observed in this study, using G*Power (Faul, Erdfelder, Land, \& Buchner, 2007). For an effect size of $d=0.17$, Study 3 had $23 \%$ power to detect a significant effect; and for an effect size of $d=0.14$, this Study had $18 \%$ power. Thus, observed condition differences may reflect truly significant differences, but this study had inadequate power to detect them. 
Assessing Support for the Null. To further probe this issue, I computed the Jeffrey-Zellner-Siow Bayes Factors for each result (Rouder, Speckman, Sun, Morey, \& Iverson, 2009). Higher Bayes Factors reflect greater support for the null. For instance, a Bayes Factor of two implies the null is twice as likely, compared to the alternative. For existential significance, the Bayes Factor was 1.20, and for coherence, 1.03. ${ }^{2}$ These values suggest that although hypotheses were not supported by statistical significance values, these data do not indicate the null was extremely likely either. Rather, the data do not indicate a strong preference either way (see Rouder, Speckman, Sun, Morey, \& Iverson, 2009, p. 233).

Mini-Meta Analysis. Thus, results for existential significance and coherence were ambiguous. In one final attempt to address this ambiguity, I conducted a mini-meta analysis (Comprehensive Meta-Analysis, Borenstein, Hedged, Higgins, \& Rothstein, 2005), comparing results for the effects of pluralistic vs. non-pluralistic rhetoric on global meaning (Studies 2 and 3), purpose, existential significance, and coherence (Study 3). Results indicated that, across Studies and measures, the average effect of condition was small but significant, $d=0.14(0.03), z=2.86, p<.001,95 \% \mathrm{CI}=[0.07,0.24]$. Results additionally indicated that heterogeneity across studies was non-significant, $Q=0.02$, $p=.88$, indicating effect sizes from Studies 2 and 3 did not differ from each other.

\section{Exploratory Analyses}

I conducted additional analyses to further probe the data. This study was administered across various waves before and during the global COVID-19 pandemic. An initial group completed the Study before the pandemic $(n=182)$; a second group completed it during the onset of the pandemic (i.e., from the time Mizzou campus closes 
through the end of the Spring 2020 semester) ( $n=116)$; and, a third group completed it roughly one year into the pandemic, during the Spring 2021 semester $(n=98)$. There certainly were qualitative differences in the college experiences of these groups. For instance, as a function of shifting to virtual learning and atypical experiences, what it means to be a Mizzou student may have been more ambiguous among the pandemic groups, especially at Time 3 . One possibility is that a more inclusive definition of what it means to be a student would have been particularly appealing during this time.

Alternatively, in the context of this environmental uncertainty, it may be that exclusivity and non-pluralism would have been especially appealing. I examined these possibilities by testing whether phase of the pandemic moderated condition effects on mood, uncertainty, meaning in life, and centrality of Mizzou identity. A significant interaction emerged only for negative affect $(F(2,390)==2.82, p=.016)$. It showed that non-pluralism led to higher negative affect at Time 2, and lower negative affect at Time 3 (and no differences at Time 1). A marginal interaction also emerged for identity centrality ( $p=.08$ ), with non-pluralism enhancing Mizzou identity centrality at Time 2, and no differences for the other groups. No other interactions approached statistical significance. Because these results do not meaningfully advance the insights offered by Study 3 data, I review them in no more detail.

\section{Brief Discussion}

In contrast to the previous studies, the manipulation in Study 3 had no effect on mood. Consistent with my predictions and previous findings, non-pluralistic rhetoric about what it means to be a Mizzou student reduced the uncertainty otherwise engendered by inclusive messaging. Condition effects on meaning in life variables were 
ambiguous. In contrast to the previous studies, tests of my predictions failed to reach statistical significance. However, mean values for each meaning variable were in the expected direction. In the case of the existential significance and coherence facets, the magnitudes of these differences were consistent with those observed in previous studies. Post-hoc sensitivity power analyses showed that, due to my inability to recruit a larger sample, this study was underpowered to detect small effect sizes. Thus, non-significant effects in this study are ambiguous.

I used two approaches to address this ambiguity. First, JZS-Bayes Factors indicated support for the null was no more likely than support for the alternative (that non-pluralistic rhetoric would boost meaning in life). Second, a mini-meta analysis suggested that when considering Studies 2 and 3 together, the combined effect of condition on global meaning (Study 2), existential significance, and coherence (Study 3) was small, but statistically significant.

Evaluating these four pieces of information together, there appears to be a mix of support for my hypotheses and the null. Results for existential significance and coherence in support of my hypotheses are compelling, despite the absence of statistically significant $p$-values. Yet, strong implications can not be drawn from these data. At one end of the spectrum of possibilities suggested by Study 3, the general effect on meaning in life of pluralistic vs. non-pluralistic rhetoric is specific to existential significance and coherence. At the opposite end, it is possible that no real effect exists for pluralistic vs. non-pluralistic rhetoric about university identity. A clearer conceptual picture could be drawn if global meaning had been influenced similarly by the manipulation across 
studies. However, condition differences for global meaning were much smaller in Study 3 than they were in Study 2.

Of course, numerous differences between Studies 2 and 3 that could help explain differences in results. First, Study 3 was conducted during an unprecedented global pandemic. Although the pandemic significantly affected participant's perceptions of existential significance and positive affect, these did not moderate the effect of condition on any of the variables in question. Additionally, these data were of considerably lower quality than those obtained in the previous studies (requiring us to drop $21 \%$ of the Study 3 sample vs. $5 \%$ on the Study 2 sample). Of course, Study 3 participants were considerably younger, and were students. It is possible that questions of American identity, which implicate a macro-group, have more potent existential functions for older adults than do questions of university identity, which implicate a micro-group, for younger students. 


\section{Chapter 5}

\section{General Discussion}

Three studies examined whether existential concerns aid our understanding of negative reactions to communications about diversity. Study 1 showed that inclusive messages, describing that there are many valid ways to be an American threatened meaning in life relative to exclusive messages conveying one right way to be American. Study 2 advanced these results by demonstrating one way to reduce this existential threat of inclusive messaging is to leverage rhetorical style. When inclusive ideals about what it means to be American were conveyed using non-pluralistic style, participants experienced higher certainty than when these were conveyed using pluralistic style. Through enhanced certainty, non-pluralistic rhetoric boosted meaning in life. Finally, Study 3 failed to replicate these patterns in a different domain — what it means to be a university student. Many aspects of these results warrant discussion.

\section{Implications for Ideology}

Numerous theories of ideology implicate uncertainty and meaning in life. As noted above, the Theory of Conservatism as Motivated Social Cognition and research supporting it show that aversion to uncertainty predisposes people to conservative ideology (Jost et al., 2003 Choma et al., 2014). Uncertainty Management Theory argues that the central function of belief endorsement is to assuage feelings of uncertainty in order to maintain a sense of meaning (Van den Bos, 2008). Uncertainty Identity Theory (Hogg, 2007) argues that ideology endorsement functions to connect humans to groups, and the resulting sense of identity provides certainty about the self. According to Significance Quest Theory (Kruglanski et al., 2018), experiences that engender 
uncertainty can initiate a significance quest whereby an individual endorses and ideology and enacts behavior consistent with that ideology on behalf of a group in order to obtain a sense of existential significance (Hogg, Kruglanski, \& Van den Bos, 2013). All of these theories, in addition Terror Management Theory (Pyszczynski, et al., 2004) (which does not implicate uncertainty) directly or indirectly suggest ideologies function to promote the sense that life is meaningful. To date, little research has empirically tested this possibility, but correlational studies indeed show ideology can serve existential meaning functions (Womick et al., 2019; Newman et al., 2019). The current findings provide experimental evidence supporting the components of these theories that implicate experiences of uncertainty and meaning in life. Specifically, exposure to inclusive messages (which conceptually overlap with liberalism, as noted in the opening quote) led to lower meaning in life than exclusive messages (which overlap with conservatism); but when these were conveyed using non-pluralistic rhetoric, this existential threat was eliminated via enhanced certainty.

However, the present findings only provide partial support for these theories. With the exception of the Theory of Conservatism as Motivated Social Cognition (Jost et al., 2003), all of these theoretical frameworks suggest that any ideology should serve uncertainty reducing and meaning boosting functions; and, that exposure to any ideological information (sometimes, only if worldview consistent, as predicted by Uncertainty and Terror Management Theories) should serve such existential functions. In contrast, the present and past research show that these in fact tend to be specific to rightwing ideology. Instead, left-wing views are dispositionally associated with lower wellbeing (Napier \& Jost, 2008; Onreat, Van Hiel, \& Dhont, 2013; Schlenker et al., 2012) 
and meaning in life (Womick et al., 2019; Newman et al., 2019); and, as I show here, exposure to messages consistent with them causally enhances uncertainty and lowers meaning in life. Thus, while research supports these theoretical frameworks in the case of right-wing ideology, findings show the opposite pattern of what theories would predict for left-wing ideology. These discrepancies present a serious challenge to existing frameworks. Future research needs to address these inconsistencies, and theoretically specify why it appears that right and left-wing views hold different capacities to serve existential functions.

One possible explanation comes from Uncertainty Identity Theory (Hogg, 2007). According to this perspective, groups that are perceived as more entitative, or defined by more homogenous members, serve better uncertainty reducing functions (Hogg, Sherman, Dierslhius, Mitner, \& Moffitt, 2007). Right-wing groups tend to be more homogenous, and thus may be perceived as more entitative. For instance, PEW research estimates $81 \%$ of Republican voters are White (vs. 59\% for Democrats) and $79 \%$ of Republican voters are Christian (vs. 52\% for Democrats), rendering these conservative groups more demographically and ideologically homogenous than their liberal counterparts (Gramlich, 2020). Thus, it may be because right-wing groups are more entitative that messages conveying conservative ideologies, and connecting people to conservative groups, are better at reducing uncertainty and promoting meaning in life.

Entitativity may also help explain differences in the results from Studies 2 and 3. For instance, "Americans" as a group may be perceived as larger, more allencompassing, and more entitative, compared to university students. Although America was founded and is often perceived as an inclusive culture (Lipsett, 1996; despite reality 
often differing from these perceptions), universities are often designed to be and perceived to be exclusive. For instance, colleges seek to maintain low admission rates because these produce perceptions of exclusivity, placing them higher on rankings lists, and making them more attractive to the most competitive students (Hartocollis \& Taylor, 2019). Thus, messaging and rhetoric about what it means to be a university student may simply not hold the same existential relevance as those about American identity. A compelling direction for future research is to further probe the role of group entitativity in the certainty and meaning functions of various religious and secular messages and ideologies.

The possibility that the existential benefits of ideology are asymmetrical remains compelling. For instance, no research has shown that the relationship between ideology and certainty, well-being, or meaning in life is curvilinear, or that exposure to left-wing ideological content enhances any of these. It may be possible that left-wing views simply are not as effective at serving these particular existential functions. Instead, it may be that left-wing ideology is produced by categorically different motives and serve entirely different psychological functions for people. Due an almost exclusive focus on right-wing ideology as a social ill, and psychology as the solution to it for the past 7 decades, our theoretical and empirical understanding of liberalism may be insufficient. For instance, although we have rigorous theoretical frameworks of right-wing ideology, its psychological anteceedants, and consequences (e.g., Jost et al., 2003; Duckitt, 2001; Altemeyer, 1981), it is unclear how these apply to left-wing views. These various theories show that underlying motivational needs for certainty, order, self-esteem, terror management, system justification (Jost et al., 2003), reduction of threat, competition 
(Altemeyer, 1981) and strict and cold child rearing (Duckitt, 2001; Feldman, 2003) predispose people to right-wing ideology. It is unclear whether the absence of these needs instead predispose people to left-wing ideology, or if there are entirely different needs driving people towards the left end of the political spectrum. Clearly, future research should be designed to better understanding the psychological antecedents and consequences of left-wing views, and the extent to which these are symmetrical, asymmetrical, or categorically different from those that predispose people to right-wing views.

A final possibility is that although mere endorsement of right-wing ideology, or exposure to right-wing consistent messaging promotes certainty and meaning in life, it may be that actual behavior is required for left-wing views to serve similar functions. Perhaps engaging in ideologically consistent collective action, such as voting, campaigning, or activism, promotes meaning in life among those on the political left. Substantial future research is required to compel forward our scientific understanding of these issues.

\section{Implications for Diversity}

The present research offers a novel context through which to view research on the way people react to demographic changes and exposure to information conveying increasing diversity. Recall that negative reactions to these implicate zero-sum beliefs, perceived group-based deprivation, and conservative ideology, and these may be especially strong among White Americans (Craig \& Richeson, 2017; See Craig, Rucker, \& Richeson, 2018; Wilkins et al., 2018; Wilkins et al., 2017; Van Assche, Roets, Van Hiel, \& Dhont, 2019; Sengupta, Osborne, \& Sibley, 2019). The findings reported here 
offer that there are existential and motivational constructs that may hold similar relevance to these processes. Despite its centrality to U.S. society, one reason people do not broadly embrace diversity may be because information about these, when conveyed using inclusive messaging and pluralistic rhetoric, enhances personal uncertainty and threatens the experience of meaning. These patterns point to one way to potentially enhance the appeal of efforts to enhance diversity. Government, industrial, and academic organizations might enhance the appeal of diversity initiatives and trainings by using internal communications about these that are expressed using non-pluralistic rhetoric. Beyond the existential appeal of non-pluralistic rhetoric identified here, it may be that such communications would also establish perceptions of norms, which may also be central to the effectiveness of efforts to enhance diversity and support for it within organizations (e.g., Asch, 1955; see Miller \& Prentice, 2016 for a review).

Automatic and unconscious associations of Whiteness with American, and White, heterosexual, male categories as cultural defaults may also drive negative reactions to diversity (Bailey \& LaFrance, 2017; Cheryan \& Monin, 2005; Hegarty, 2017; Smith \& Zarate, 1992). Specifically, these cognitive associations suggest people (especially those who identify as White, and for whom American identity is central to the self, Devos \& Banaji, 2005) generally view what it means to be American as a function of racial, gender and sexual group membership. The present results point to one compelling way to reduce negative reactions that may stem from these sources to diversity communications: To enhance perceived certainty and meaning in life by convey inclusive messaging using non-pluralistic rhetoric. However, if at least part of the source of negative reactions to diversity is motivated by unconscious definitions of American identity, it may suggest 
that they could be combatted at numerous levels. The present research represents a manipulation occurring at the conscious level. Although the effectiveness of interventions targeting implicit associations presents unique challenges (Forscher et al., 2019), it may be that cognitive-behavioral interventions could be leveraged to promote greater embracement of diversity, inclusive messaging, and pluralistic rhetoric. For instance, a meta-analysis of 17 different interventions among 20,000 participants showed those involving counterstereotypic exemplars and development of strategies to override such associations are effective (Calachini, Lai \& Klauer, 2020). Although these results have been demonstrated only for implicit racial bias, it may be that similar interventions could be leveraged to target those concerning cultural defaults and what it means to be American. These may enable individuals to find greater appeal in inclusive messaging, pluralistic rhetoric, and diversity broadly.

\section{Mood and Meaning in Life}

The current results showed that inclusive messaging affects well-being on two separable levels. Despite the robust link between mood and meaning in life (King et al., 2006), condition had divergent effects on these variables. Exposure to inclusive messaging simultaneously enhance a hedonic indicator of well-being, mood, while also leading to lower perceptions of meaning in life, typically considered a eudaimonic indicator. These divergent results may point to one reason why conflicts about diversity and representation persist in many areas of modern life. On one level, results for mood show that inclusive messages represent a feel good idea, potentially driving the general explicit and intuitive appeal of these notions. Yet, on another level, this feel good message renders the world and one's place it in less certain, threatening the experience of 
meaning in life. This latter finding may speak to why, despite its affective benefits, cultural diversity remains challenging in modern society.

\section{Limitations}

Numerous methodological considerations limit the inferences that can be drawn from these studies. First, the present research relied entirely on online and student convenience samples. It is unclear whether these results would generalize to the national population, or to other cultures. Second, these studies relied exclusively on self-report measures. Although self-report is the best way to measure subjective experiences, such as well-being, future research should address behavioral implications of inclusive vs. exclusive messaging, and pluralistic vs. non-pluralistic rhetoric. For instance, a fruitful direction might entail field research designed to test whether using non-pluralistic rhetoric to convey inclusive messaging in the context of diversity trainings enhances their effectiveness.

Lastly, the effect sizes in the current studies were notably small. Study 3 had less than $25 \%$ power to detect the hypothesized effects. Can an effect that is so small it requires massive power to detect be meaningful in the real world? Consider that the manipulation in Studies 2 and 3 relied on a single sentence, presented on one occasion online, in written text. In the real world, these messages and rhetoric would likely be presented with accompanying cues that would enhance the magnitude of their effect on uncertainty and meaning in life, including audio, video, non-verbal communication, and the presence of other people. They would likely be repeated over time. In contrast to the present studies, which identified the author of the passage as a previous participant, in the real world these messages would likely be delivered by an authority figure. Thus, despite 
their small magnitude, this subtle manipulation can be leveraged at scale and in combination with other cues that would likely affect real-world change.

\section{Conclusion}

Inclusive messaging about what it means to be an American lowers perceptions of life's meaningfulness. The highest ideals of U.S. society involve inclusivity. Working towards a more representative future necessitates inclusive messaging. Non-pluralistic rhetorical style can be leveraged to buffer uncertainty and meaning in life against the negative effects of inclusive messaging about what it means to be American (although these patterns do not extend to what it means to be a university student). Future research should examine the extent to which these affect attitudes towards diversity, and whether they can produce lasting real-world change. 


\section{Footnotes}

${ }^{1}$ Recent research suggests this may be the case of extreme ideology broadly, rather than left-right differences (see Zimgrod et al., 2020).

${ }^{2}$ Although perhaps unintuitive, these values are correct. Bayes Factors increase as a function of effect size, the idea being that when all else is held constant, if a larger effect size does not reach statistical significance, it is less likely to be a true effect than a smaller effect size. 


\section{References}

Altemeyer, B. (1981). Right-wing authoritarianism. Winnipeg, Canada: University of Manitoba Press.

Altemeyer, B. (1998). The other “authoritarian personality.” In M.P. Zanna (Ed.), Advances in experimental social psychology, 30, 47-92. San Diego: Academic Press. doi: 10.1016/S0065-2601(08)60382-2

Asch, S. (1955). Opinions and social pressure. Scientific American, 193, 31-35.

Bailey, A., \& LeFrance, M. (2017). Who counts as human? Antecedents to androcentric behavior. Sex Roles, 76, 682-693

Borenstein, M., Hedged, L., Higgins, J., \& Rothstein, H. (2005). Comprehensive MetaAnalysis (Version 3). Englewood, NJ: Biostat.

Calanchini, J., Lai, C. K., \& Klauer, K. C. (2020). Reducing implicit racial preferences: III. A process-level examination of changes in implicit preferences. Journal of Personality and Social Psychology. doi:10.1037/pspi0000339

Carney, D. R., Jost, J. T., Gosling, S. D., \& Potter, J. (2008). The secret lives of liberals and conservatives: Personality pofiles, interaction styles, and the things they leave behind. Political Psychology, 29, 807-840.

Cheryan, S., \& Monin, B. “Where are you really from?”: Asian Americans and identity denial. Journal of Personality and Social Psychology, 89, 717-730.

Choma, B., Hodson, G., Hoffarth, M. R., Charlesford, J. J., \& Hafer, C. L. (2014).

Reasoning ability and ideology: Inaccuracies in hierarchical category relations (but not numerical ability) are associated with right-wing authoritarianism. Journal of Individual Differences, 3, 177-183. doi:10.1027/1614-0001/a000142 
Choma, B. L., Hodson, G., Jagayat, A., Hoffarth, M. R. (2020). Right-wing ideology as a predictor of collective action across four political issue domains. Political Psychology, 41, 303-322.

Costin, V., \& Vignoles, V. L. (2019). Meaning is about mattering: Evaluating coherence, purpose and existential mattering as precursors of meaning in life judgements. Journal of Personality and Social Psychology, in press.

Craig, M., \& Richeson, J. A. (2014). On the precipice of a "Majority-Minority" America: Perceived status threat from the racial demographic shift affects White Americans' political ideology. Psychological Science, 25, 1189-1197.

Craig, M., \& Richeson, J. A. (2017). Information about the US racial demographic shift triggers cocerns about anti-White discrimination among the prospective White minority." PLOS One, 1-20

Craig, M., Rucker, J. M., \& Richeson, J. A. (2018). The pitfalls and promise of increasing racial diversity: Threat contact and race relations in the $21^{\text {st }}$ century. Current Directions in Psychological Science, 27, 188-193

Dar, K. A., \& Iqbal, N. (2019). Religious commitment and well-being in college students: Examining conditional indirect effects of meaning in life. Journal of religion and health, 58(6), 2288-2297.

Devos, T., \& Banaji, M. R. (2005). American = White? Journal of Personality and Social Psychology, 88, 447-466.

DiAngelo, R. J. (2018). White fragility: Why its so hard for White people to talk about racism. Boston: Beacon Press.

Dieckman, J., Steffen, M., C., \& Methner, N. Back to the roots: When diversity evokes 
increased group-based conventionalism. Group Processes \& Intergroup Relations, $21,351-367$.

Duckitt, J. (2001). A dual-process cognitive-motivational theory of ideology and prejudice. Advances in Experimental Social Psychology, 33, 41-113. doi: 10.1016/S0065-2601(01)80004-6

Edwards-Levy, A. (April 4, 2018). In 1968, Nearly a third of Americans said MLK brought his assassination on himself. Huffington Post. Retrieved from: https://www.huffpost.com/entry/in-1968-nearly-a-third-of-americans-said-mlkbrought-his-killing-on-himself_n_5ac51373e4b0aacd15b7d37b

Faul, F., Erdfelder, E., Lang, A. G., \& Buchner, A. (2007). G*Power 3: A flexible statistical power analysis program for the social behavioral, and biomedical sciences. Behavior Research Methods, 39, 175-191.

Feldman, S. (2003). Enforcing social conformity: A theory of authoritarianism. Political Psychology, 24, 41-74. doi: 10.1111/0162-895X.00316

Forscher, P. S., Lai, C. K., Axt, J. R., Ebersole, C. R., Herman, M., Devine, P. G., \& Nosek, B. A. (2019). A meta-analysis of procedures to change implicit measures. Journal of Personality and Social Psychology, 117, 522-559.

George, L. S., \& Park, C. L. (2016). The Multidimensional Existential Meaning Scale: A tripartite approach to measuring meaning in life. The Journal of Positive Psychology, 12, 613-627. doi:10.1080/17439760.2016.1209546

Goh, J. X., Hall, J. A., \& Rosenthal, R. (2016). Mini Meta-analysis of your own studies: Some arguments and a primer on how. Social and Personality Psychology Compass, 10, 535-549. doi:10.1111/spc3.12267 
Gramlich, J. (October 26, 2020). What the 2020 electorate looks like by party, race, and ethnicity, age, education, and religion. Pew Research Center. Retrieved from: https://www.pewresearch.org/fact-tank/2020/10/26/what-the-2020-electoratelooks-like-by-party-race-and-ethnicity-age-education-and-religion/

Greco, V., \& Roger, D. (2001). Coping with uncertainty: The construction and validation of a new measure. Personality and Individual Differences, 31, 519-534.

Hagaa, D. (2020). Need for viewpoint diversity in clinical psychology. Clinical Psychology: Science and Practice, 27.

Hartocollis, A., \& Taylor, K. (March 29, 2019). Elite colleges announce record low admission rates in wake of college cheating scandal. The New York Times. Retrieved from: https://www.nytimes.com/2019/03/29/us/college-admissionsrates.html

Haslam, N., Dakin, B. C., Fabiano, F., McGrath, M. J., Rhee, J., et al. (2020). Harm inflation: Making sense of concept creep. European Review of Social Psychology, 254-286.

Hasson, Y., Tamir, M., Brahms, K. S., Cohrs, J. C., Halperin, E. (2018). Are liberals and conservatives equally motivated to feel empathy toward others? Personality and Social Psychology Bulletin, 44, 1449-1459.

Hegarty, P. (2006). Undoing androcentric explanations of gender differences: Explaining the 'effect to be predicted.' Sex Roles, 55, 861-867

Hegarty, P. (2017). On the failure to notice that White people are White: Generating and testing hypotheses in the celebrity guessing game. Journal of Experimental Psychology: General, 146, 41-62. 
Hegarty, P., \& Pratto, F. (2001). The effects of social category norms and stereotypes on explanations for intergroup differences. Journal of Personality and Social Psychology, 80, 723-735.

Heintzelman, S. J., \& King, L. A. (2014). (The feeling of) Meaning-as-information. Personality and Social Psychology Review, 1-15. doi:10.1077/1088868313518487

Heintzelman, S. J., \& King, L. A. (2016). Meaning in life and intuition. Journal of Personality and Social Psychology, 110, 477-492.

Heintzelman, S. J., \& King, L. A. (2019). Routines and Meaning in Life. Personality and Social Psychology Bulletin, 1-12. doi: 10.1177/0146167218795133

Heintzelman, S.J., Trent, J., \& King, L.A. (2013). Encounters with objective coherence and the experience of meaning in life. Psychological Science, 24, 991-998.

Hicks, J. A., \& King, L. A. (2009). Positive mood and social relatedness as information about meaning in life. Journal of Positive Psychology, 4, 471-482.

Hirsh, J. B., DeYoung, C. G., Xu, X., Peterson J. B. (2010). Compassionate liberals and polite conservatives: Associations of agreeableness with political ideology and moral values. Personality and Social Psychology Bulletin, 36, 655-664.

Hogg, M. A. (2007). Uncertainty-identity theory. In M. Zanna (Ed.), Advances in experimental social psychology (pp. 69-166). San Diego, CA: Elsevier.

Hogg, M. A., Sherman, D. K., Dierselhius, J., Maitner, A. T. Moffitt, G. (2007). Uncertainty, entitativity, and group identification. Journal of Experimental Social Psychology, 43, 135-142. Doi: 10.1016/j.jesp.2005.12.008

Hogg, M. A., Van den Bos, K., Kruglanski, A. (2013). Uncertainty and the roots of 
extremism. Journal of Social Issues, 69, 407-418.

Honeycutt, N., Jussim, L. (2020). A model of political bias in social science research. Psychological Inquiry, 31, 73-85.

Jessani, Z., \& Harris, P. B. (2018). Personality, politics, and denial: Tolerance of ambiguity, political orientation and disbelief in climate change. Personality and Individual Differences, 131, 121-123.

Jost, J. T., Glaser, J., Kruglanski, A. W., \& Sulloway, F. J. (2003). Conservatism as motivated social cognition. Psychological Bulletin, 129, 339-375. doi: 1037/00332909.129.3.339

Jost, J. T., \& Hunyday, O. (2018). Mass psychology in the age of Trump. Democracy Journal of Ideas, 48. Retrieved from: https://democracyjournal.org/magazine/48/mass-psychology-in-the-age-of-trump/

Jost, J.T., Stern, C., Rule, N., \& Sterling, J. (2017). The politics of fear: Is there an ideological asymmetry in existential motivation? Social Cognition, 35, 324-353.

Kashdan, T. B., Biswas-Diener, R., \& King, L. A. (2008). Reconsidering happiness: The costs of distinguishing between hedonics and eudaimonia. Journal of Positive Psychology, 8, 219-233.

Kaufman, E. (2021). Academic freedom in crisis: Punishment, political discrimination, and self-censorship. Center for the Study of Partisanship and Ideology, 2, 1-190.

King, L. A., Hicks, J. A., Krull, J. L., \& Del Gaiso, A. K. (2006). Positive affect and the experience of meaning in life. Journal of Personality and Social Psychology, 90, 179-196. doi: 10.1037/0022-3514.90.1.179 
King, L.A., \& Hicks, J. A. (2021). The Science of Meaning in Life. Annual Review of Psychology, 72, 561-584.

Kraus, M. W., Onyeador, I. M., Daumeyer, N. M., Rucker, J. M., \& Richeson, J. A. (2019). The misperceptions of racial economic inequality. Perspectives on Psychological Science, 14, 899-921.

Krause, N., \& Hayward, R. D. (2014). Assessing stability and change in a second-order confirmatory factor model of meaning in life. Journal of Happiness Studies, 15, 237253.

Kruglanski, A. W., \& Webster, D. M. (1996). Motivated closing of the mind: "Seizing" and "freezing." Psychological Review, 103, 263-283.

Kruglanski, A. W., Jasko, K., Webber, D., Chernikova, M., \& Molinario, E. (2018). The making of violent extremists. Review of General Psychology, 22, 107-120. doi:10.1037/gpr0000144

Lilienfeld, S. O. (2017). Microaggressions: Strong claims, inadequate evidence. Perspectives on Psychological Science, 12, 138-169.

Lipsett, S. (1996). American exceptionalism: A double-edged sword. New York: Norton. Miller, D. T., \& Prentice, D. A. (2016). Changing norms to change behavior. Annual Review of Psychology, 67, 339-361.

Mishel, M. H. (1981). The measurement of uncertainty in illness. Nursing Research, 30, 258-263.

Napier, J., \& Jost, J. T. (2008). Why are conservatives happier than liberals? Psychological Science, 19, 565-572. doi:10.1111/j.1467-9280.2008.02124.x

Newman, D. B., Schwarz, N., Graham, J., \& Stone, A. A. (2019). Conservatives report 
greater meaning in life than liberals. Social Psychological and Personality Science, 10, 494-503. doi: 10.1177/1948550618768241

Onreat, E., Van Heil, A., \& Dhont, K. (2013). The relationship between right-wing ideological attitudes and psychological well-being. Personality and Social Psychology Bulletin. doi: 10.1177/0146167212378199

Phillips, J., De Freitas, J., Mott, C., Gruber, J., \& Knobe, J. (2017). True happiness: The role of morality in the folk concept of happiness. Journal of Experimental Psychology: General, 146, 165-181

Popper, K. R. (1945). The open society and its enemies: Volume II, Hegel and Marx. Routledge Classics, New York.

Pratto, F., Korchmaro, J., \& Hegarty, P. (2007). When race and gender go without saying. Social Cognition, 25, 241-247.

Pyszczynski, T., Greenberg, J., Solomon, S., Arndt, J., \& Schimel, J. (2004). Why do people need self-esteem?: A theoretical and empirical review. Psychological Bulletin, 130, 435-468. doi: 10.1037/0033-2909.130.3.435.

Richeson, J. A. (2020). Americans are determined to believe in Black progress whether it is happening or not. The Atlantic. Retrieved from: https://www.theatlantic.com/magazine/archive/2020/09/the-mythology-of-racialprogress/614173/

Rivera, G., Vess, M., Hicks, J. A., \& Routledge, C. (2019). Awe amd Meaning: Elucidating complex effects of awe experiences on meaning in life. European Journal of Social Psychology, 50, 392-405.

Rouder, J. N., Speckman, P. L., Sun, D., Morey, R. D., \& Iverson, G. (2009). Bayesian $t$ 
tests for accepting and rejecting the null hypothesis. Psychonomic Bulletin \& Review, 16, 225-237.

Ryff, C. D. (2018). Well-being with soul: Science in pursuit of human potential.

Perspectives on Psychological Science, 13, 242-248. doi:10.1177/1745691617699836

Scott, A., Schimel, J., \& Sharp, M. (2021). Long live A(me)rica! An examination of the interplay between nationalistic-symbolic immortality striving and belief in life after death. Journal of Personality and Social Psychology, 120, 861-881.

Schlenker, B. R., Chambers, J. R., \& Le, B. M. (2012). Conservatives are happier than liberals, but why? Political ideology, personality, and life satisfaction. Journal of Research in Personality, 46, 127-146. doi: 10.1016/j.jrp.2011.12.009

Schoor, C. (2017). In the theatre of political style: Touches of populism, pluralism, and elitism in speeches of politicians. Discourse \& Society, 28, 657-676

Schwarz, N. \& Clore, G. (2003). Mood as information: 20 years later. Psychological Inquiry, 14, 296-303.

Sengupta, N. K., Osborne, D., \& Sibley, C. G. (2019). On the psychological function of nationalistic “whitelash.” Political Psychology, 40, 759-775.

Sidianius, J., Pratto, F., \& Bobo, L. (1996). Racism, conservatism, affirmative action, and intellectual sophistication: A matter of principled conservatism or group dominance? Journal of Personality and Social Psychology, 70, 476-490.

Smith, E. R., \& Zarate, M. A. (1992). Exemplar-based model of social judgement. Psychological Review, 99, 3-21

Steger, M. F., \& Frazier, P. (2005). Meaning in life: One link in the chain from 
religiousness to well-being. Journal of Counseling Psychology, 52, 574. doi:

$10.1037 / 0022-0167.52 .4 .574$

Steger, M. F., Frazier, P., Oishi, S., \& Kaler, M. (2006). The meaning in life questionnaire:

Assessing the presence of and search for meaning in life. Journal of Counseling Psychology, 53, 80-93. doi: 10.1037/0022-0167.53.1.80

Tetlock, P. E. (1983). Cognitive style and political ideology. Journal of Personality and Social Psychology, 45, 118-126.

Tov, W., \& Lee, H. W. (2016). A closer look at the hedonics of everyday meaning and satisfaction. Journal of Personality and Social Psychology, 111, 585-609. http://dx.doi.org/10.1037/pspp0000081

Trent, J., Lavelock, C., \& King, L. A. (2013). Processing fluency, positive affect, and judgments of meaning in life. The Journal of Positive Psychology, 8, 135-139. doi: $10.1080 / 17439760.2013 .772220$

van den Bos, K. (2009). Making sense of life: The existential self trying to deal with personal uncertainty. Psychological Inquiry, 20, 197-217. doi:

$10.1080 / 10478400903333411$

Van Assche, J., Roeta, A., Van Hiel, A., \& Dhont, K. (2019). Diverse reactions to ethnic Diversity: The role of individual differences in authoritarianism. Current Directions in Psychological Science.

Ward, S.J., \& King, L. A. (2016). Socrates' Dissatisfaction, a Happiness Arms Race, and the Trouble with Eudaimonic Well-being. To appear in J. Vitters $\emptyset$ (Ed.), Handbook of Eudaimonic Wellbeing. (pp.523-531). New York: Springer. 
Wilkins, C. L., Wellman, J. D., Babbitt, L. G., Toosi, N. R., \& Schad, K. D. (2015). You can win but I can’t lose: Bias against high-status groups increases their zero-sum beliefs about discrimination. Journal of Experimental Social Psychology, 57, 114.

Wilkins, C. L., Hirsch, A. A., Kaiser, C. R., \& Inkles, M. P. (2017). The threat of racial progress and the self-protective nature of perceiving anti-White bias. Group Processes and Intergroup Relations, 20, 801-812.

Winegard, B. M., \& Clark, C. J. (2020). Without contraries is no progression. Psychological Inquiry, 31, 94-101.

Womick, J., Ward, S. J., Heintzelman, S. J., Woody, B., \& King, L. A. (2019). The Existential Function of Right-wing Authoritarianism. Journal of Personality.

Womick, J., Woody, B., \& King, L. A. (invited revision). Religious fundamentalism, right-wing authoritarianism, and meaning in life.

You, S., \& Lim, S. A. (2019). Religious Orientation and Subjective Well-being: The Mediating Role of Meaning in Life. Journal of Psychology and Theology, 47, 34-47.

Zhang, H., Hook, J. N., Farrell, J. E., Mosher, D. K., Van Tongeren, D. R., \& Davis, D. E. (2018). The effect of religious diversity on religious belonging and meaning: The role of intellectual humility. Psychology of Religion and Spirituality, 10, 72-78. doi:10.1037/rel0000108

Zimigrod, L., Rentfrow, P. J., \& Robbins, T. W. (2020). The partisan mind: Is extreme political partisanship related to cognitive inflexibility? Journal of Experimental Psychology: General, 149, 407-418. 
Table 1. Correlations Among Measures, Study 1

\begin{tabular}{|c|c|c|c|c|c|c|}
\hline & Pur & Coh & Sign & PA & NA & Evals \\
\hline MIL & $.73 * *$ & $.78^{* *}$ & $.65 * *$ & $.35^{* *}$ & $-.22 * *$ & $.24 * *$ \\
\hline Purpose & & $.74 * *$ & $.65^{* *}$ & $.22 * *$ & $-.29 * *$ & $.15^{* *}$ \\
\hline Coherence & & & $.67 * *$ & $.27 * *$ & $-.33 * *$ & $.17 * *$ \\
\hline Significance & & & & $.24 * *$ & $-.28 * *$ & $.17 * *$ \\
\hline PA & & & & & $-.09 * *$ & $.54 * *$ \\
\hline NA & & & & & & $-.28 * *$ \\
\hline
\end{tabular}

Note. $N=826 . * p<.05, * * p<.001$. MIL $=$ global meaning in life; Pur=purpose;

Coh=coherence Sign=significance $; \mathrm{PA}=$ positive affect NA = negative affect;

Evals $=$ message evaluations 
Table 2. Effects of Condition on Mood, Study 1

\begin{tabular}{llllll} 
Study & & Control & Pluralist & Non-Pluralist & Effect of Condition \\
\hline 3 & $n$ 's & 519 & 533 & 528 & \\
& & & & & \\
& PA & $2.77(1.72)_{\mathrm{a}}$ & $4.12(1.83)_{\mathrm{b}}$ & $3.46(1.89)_{\mathrm{c}}$ & $F(2,1577)=71.91, d=0.61 * *$ \\
NA & $2.18(1.36)_{\mathrm{a}}$ & $1.97(1.37)_{\mathrm{a}}$ & $2.53(1.62)_{\mathrm{b}}$ & $F(2,1577)=19.81, d=0.32^{* *}$
\end{tabular}

Note. $\mathrm{PA}=$ Positive Affect, NA=Negative Affect. ${ }^{*} p<.001$. Means in the same row with differing subscripts are significantly different, $p<.05$, Bonferroni corrected. 
Table 3. Correlations Among Measures, Study 2

\begin{tabular}{c|cccccc}
\multirow{2}{*}{ Uncertainty } & MIL & PA & NA & Agree & Easy & ID \\
\cline { 2 - 7 } & $-.27^{*}$ & -.02 & $.64^{*}$ & $-.17^{*}$ & $-.39^{*}$ & $-.15^{*}$ \\
Meaning in Life & & $.29 *$ & $-.13^{*}$ & $.17^{*}$ & $.16^{*}$ & $.31^{*}$ \\
Positive Affect & & & -.01 & $.59^{*}$ & $.16^{*}$ & $.45^{*}$ \\
Negative Affect & & & & $-.27^{*}$ & $-.32^{*}$ & -.05 \\
Agreement & & & & & $.38^{*}$ & $.35^{*}$ \\
$\quad$ & & & & & & $.10^{*}$
\end{tabular}

Note. Pairwise $N=1147 .{ }^{*} p<.001$. MIL = meaning in life; $\mathrm{PA}=$ positive affect; $\mathrm{NA}=$ negative affect; Agree $=$ agreement with author; Easy = ease of comprehending message; ID = centrality of American Identity. 
Table 4. Correlations Among Measures, Study 3

\begin{tabular}{|c|c|c|c|c|c|c|c|}
\hline & MIL & Sign & Pur & Coh & PA & NA & ID \\
\hline Uncertainty & $-.31 * *$ & $-.16^{* *}$ & $-.40 * *$ & $-.35 * *$ & $-.25 * *$ & $.33 * *$ & $-.22 * *$ \\
\hline $\begin{array}{l}\text { Meaning in } \\
\text { Life }\end{array}$ & & $.63 * *$ & $.65^{* *}$ & $.77 * *$ & $.44 * *$ & $-.20 * *$ & $.24 * *$ \\
\hline Significance & & & $.53 * *$ & $.60 * *$ & $.43 * *$ & $-.12 *$ & $.26 * *$ \\
\hline Purpose & & & & $.64 * *$ & $.30 * *$ & $-.21 * *$ & $.29 * *$ \\
\hline Coherence & & & & & $.38 * *$ & $-.29 * *$ & $.17 * *$ \\
\hline $\begin{array}{c}\text { Positive } \\
\text { Affect }\end{array}$ & & & & & & $-.20 * *$ & $.21 * *$ \\
\hline $\begin{array}{c}\text { Negative } \\
\text { Affect }\end{array}$ & & & & & & & .05 \\
\hline
\end{tabular}

Note. Pairwise $N=396 . *^{*} p<.001 ;{ }^{*} p<.031$. MIL = meaning in life; Sign=significance; Pur=purpose; $\mathrm{Coh}=$ coherence $\mathrm{PA}=$ positive affect; $\mathrm{NA}=$ negative affect; ID = centrality of American Identity; 
Figure 1. Mediation of the Effect of Condition by Facets of Meaning, Study 1

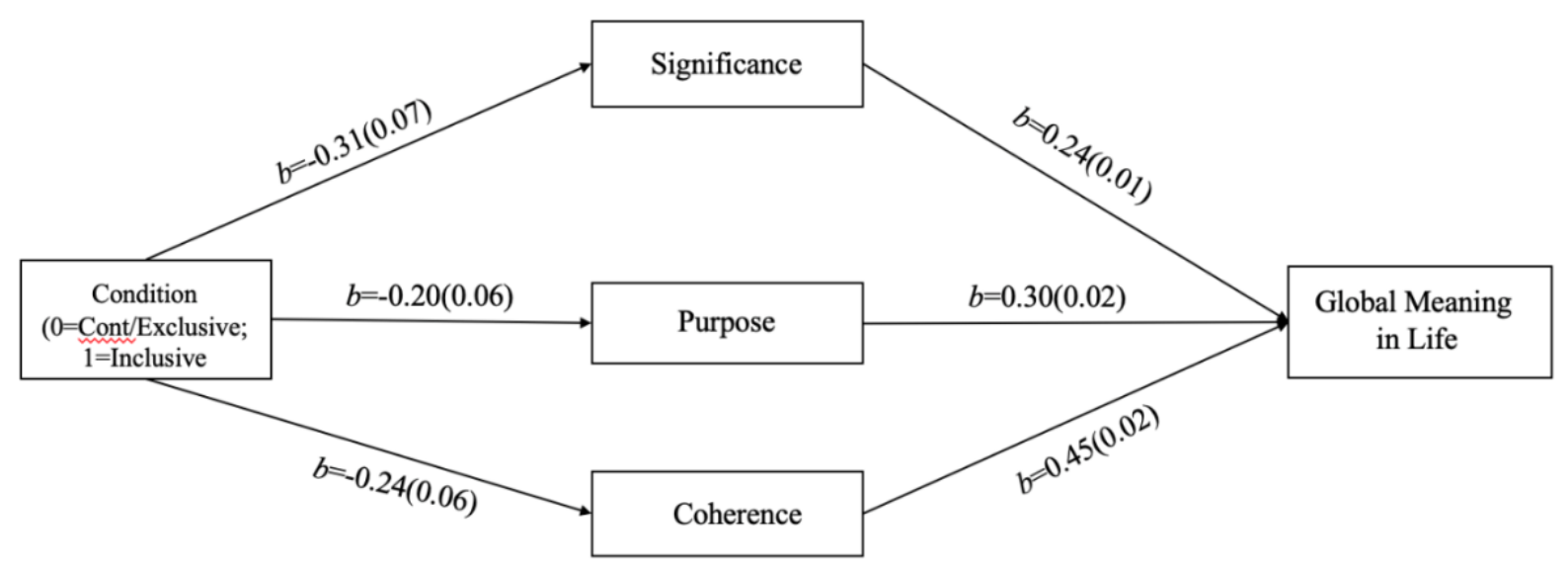

Note. All solid paths are significant, $p<.001$. Coefficients are unstandardized regression weights (SE). Without controlling for meaning, the effect of condition on global meaning was $-0.31(.07)$, and when accounting for the facets, it was no longer significant, $-.03(.03)$ 
Figure 2. Mediation of Condition Effect on Global Meaning by Uncertainty, Study 2

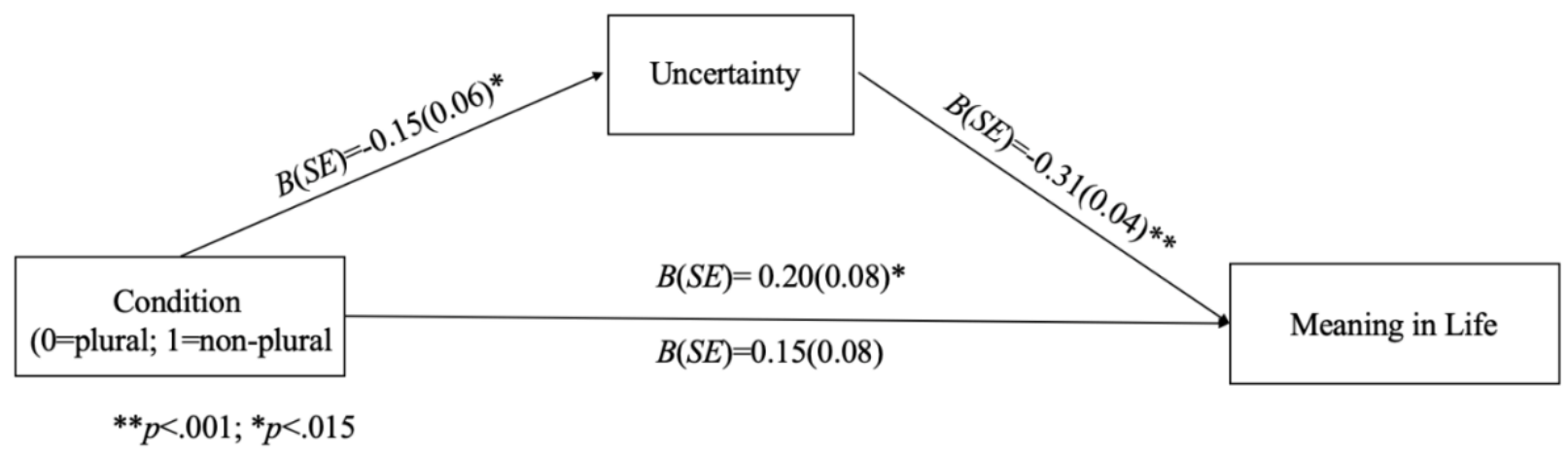




\section{Appendix A}

All items included in Study 1:

Please respond to the following items based on how the passage made you feel

\begin{tabular}{|l|l|l|l|l|l|l|}
\hline 1 & 2 & 3 & 4 & 5 & 6 & 7 \\
\hline $\begin{array}{l}\text { Not at all } \\
\text { true }\end{array}$ & & & & & & $\begin{array}{l}\text { Extremely } \\
\text { true }\end{array}$ \\
\hline
\end{tabular}

Global Meaning in life

I understand my life's meaning.

My life has a clear sense of purpose.

I have discovered a satisfying life purpose.

I have a good sense of what makes my life meaningful.

My life has no clear purpose.

\section{Coherence}

I can make sense of the things that happen in my life.

Looking at my life as a whole, things seem clear to me.

I can't make sense of events in my life.

My life feels like a sequence of unconnected events.

\section{Purpose}

I have a good sense of what I am trying to accomplish in life.

I have certain life goals that compel me to keep going.

I don't know what I am trying to accomplish in life.

I don't have compelling life goals that keep me going.

\section{Mattering}

Whether my life ever existed matters even in the grand scheme of the universe.

Even considering how big the universe is, I can say that my life matters.

My existence is not significant in the grand scheme of things.

Given the vastness of the universe, my life does not matter.

Note: Italicized items are reverse-scored

\section{Mood}

Indicate the extent you the passage made you feel this way

\begin{tabular}{|l|l|l|l|l|l|l|}
\hline 1 & 2 & 3 & 4 & 5 & 6 & 7 \\
\hline Not at all & & & & & & $\begin{array}{l}\text { Very } \\
\text { much }\end{array}$ \\
\hline
\end{tabular}

Anxious

Cheerful 
Frustrated

Happy

Pleased

Sad

Enjoyment/Fun

Angry

Worried

\section{Evaluations}

Using this scale, please indicate your response the following questions.

\begin{tabular}{|l|l|l|l|l|l|l|}
\hline 1 & 2 & 3 & 4 & 5 & 6 & 7 \\
\hline Not at all & & & & & & Very much \\
\hline
\end{tabular}

How much did you like the author of the passage that you read.

How intelligent is the writer of the passage.

Did you find the writer's position to be fair.

I agreed with the writer's beliefs in the essay

I am morally better than the writer of this essay

In America, do you see yourself as a minority?

How much does this author threaten your identity as an American?

According to this person, are you a good American?

According to the author, how easy is it to be an American?

According to the author, how hard is it to be an American?

In American, do you see yourself as a majority?

From the view of the author, are the following people good Americans?

\begin{tabular}{|l|l|l|l|l|l|l|}
\hline 1 & 2 & 3 & 4 & 5 & 6 & 7 \\
\hline Not at all & & & & & & $\begin{array}{l}\text { Very } \\
\text { much }\end{array}$ \\
\hline
\end{tabular}

_Colin Kaepernick

_Donald Trump

_Barrack Obama

_Kanye West

Please rate the extent to which the following are American

\begin{tabular}{|l|l|l|l|l|l|l|}
\hline 1 & 2 & 3 & 4 & 5 & 6 & 7 \\
\hline Not at all & & & & & & $\begin{array}{l}\text { Very } \\
\text { much }\end{array}$ \\
\hline
\end{tabular}

_pizza

_country music

_hip hop

_guns

-racism

_black people

_liberals 
_conservative

_Donald Trump

_Barrack Obama

_French fries

_War

_The KKK

_White people

How much would you pay for this American flag?

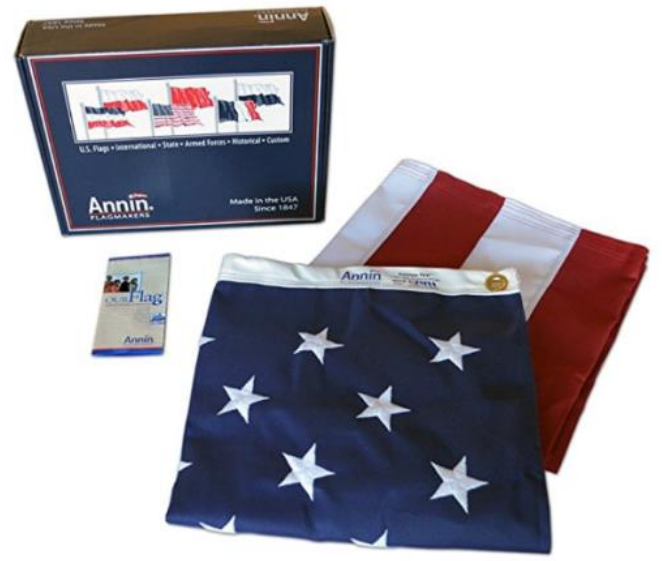

How much do you think it would be worth to fix up the Statue of Liberty?

How much would you be willing to donate to the Wounded Warrior group (a nonprofit Veterans organization)?

How much would you sell your American citizenship for?

If you were not an American citizen, how much would you be willing to pay for American citizenship?

\begin{tabular}{|l|l|l|l|l|l|l|}
\hline 1 & 2 & 3 & 4 & 5 & 6 & 7 \\
\hline $\begin{array}{l}\text { Not at all } \\
\text { true }\end{array}$ & & & & & & $\begin{array}{l}\text { Extremely } \\
\text { true }\end{array}$ \\
\hline
\end{tabular}

I am proud to be American.

Regardless of how many people may find it wrong, I will always voice my opinion.

I speak up when things need to be said.

America is the best country in the world.

When sharing my opinions on political issues, I feel scared as to what others may think. 
I have pride in my country.

Being American means nothing to me at this point.

I feel like people are silenced based on their beliefs.

America is a melting pot.

\section{Intrinsic Religiosity}

Please rate the following items based on how much you agree with the statements.

\begin{tabular}{|c|c|c|c|c|c|c|}
\hline $\begin{array}{c}\text { I Strongly } \\
\text { Disagree }\end{array}$ & & $\begin{array}{c}\text { I'm not } \\
\text { sure }\end{array}$ & & & $\begin{array}{c}\text { I Strongly } \\
\text { Agree }\end{array}$ \\
\hline 1 & 2 & 3 & 4 & 5 & 6 & 7 \\
\hline
\end{tabular}

1. I try hard to live all my life according to my religious beliefs.

2. My whole approach to life is based on my religion

\section{In-group Threat}

Please indicate how anxious, fearful, or concerned do you feel about the following potential life eventualities, using the scale below.

\begin{tabular}{|l|l|l|l|l|l|l|}
\hline 1 & 2 & 3 & 4 & 5 & 6 & 7 \\
\hline Not at all & & & & & & $\begin{array}{l}\text { Very } \\
\text { Much }\end{array}$ \\
\hline
\end{tabular}

1. Jobs are being taken away from my cultural group

2. My cultural group is being publicly targeted and humiliated

3. My cultural group is quickly becoming a minority

4. My cultural group is losing its social standing

5. My ethnic/racial group is being segregated from mainstream society

\section{All Items included in Study 2}

\section{Uncertainty}

Please respond to the following items using the scale below, based on how the passage made you feel

\begin{tabular}{|l|l|l|l|l|l|l|}
\hline 1 & 2 & 3 & 4 & 5 & 6 & 7 \\
\hline $\begin{array}{l}\text { Strongly } \\
\text { Disagree }\end{array}$ & & & & & & $\begin{array}{l}\text { Strongly } \\
\text { Agree }\end{array}$ \\
\hline
\end{tabular}

Right now I feel uncertain

Currently, I'm not sure what to think is right

At this moment, I don't feel sure of what it means to be an American

Reading the passage made me feel uncertain about my own views

I currently feel confused about American identity 


\section{Meaning in Life}

Please respond to the following items based on how the passage made you feel

\begin{tabular}{|l|l|l|l|l|l|l|}
\hline 1 & 2 & 3 & 4 & 5 & 6 & 7 \\
\hline $\begin{array}{l}\text { Not at all } \\
\text { true }\end{array}$ & & & & & $\begin{array}{l}\text { Extremely } \\
\text { true }\end{array}$ \\
\hline
\end{tabular}

I understand my life's meaning.

I am looking for something that makes my life meaningful.

I am always looking to find my life's purpose.

My life has a clear sense of purpose.

I have discovered a satisfying life purpose.

I have a good sense of what makes my life meaningful.

I am always searching for something that makes my life feel significant.

I am seeking a purpose or mission for my life.

My life has no clear purpose.

I am searching for meaning in my life.

\section{Mood}

Indicate the extent you the passage made you feel this way

\begin{tabular}{|l|l|l|l|l|l|l|}
\hline 1 & 2 & 3 & 4 & 5 & 6 & 7 \\
\hline Not at all & & & & & & $\begin{array}{l}\text { Very } \\
\text { much }\end{array}$ \\
\hline
\end{tabular}

Anxious

Cheerful

Frustrated

Happy

Pleased

Sad

Enjoyment/Fun

Angry

Worried

\section{Evaluations}

Please respond to the following items about the author of passage you just read, using the scale below

\begin{tabular}{|l|l|l|l|l|l|l|}
\hline 1 & 2 & 3 & 4 & 5 & 6 & 7 \\
\hline $\begin{array}{l}\text { Strongly } \\
\text { Disagree }\end{array}$ & & & & & & $\begin{array}{l}\text { Strongly } \\
\text { Agree }\end{array}$ \\
\hline
\end{tabular}


How easy was it to read the passage?

How much do you agree with the author?

How easy was it to understand the message?

Identity Centrality

\begin{tabular}{|l|l|l|l|l|l|l|}
\hline 1 & 2 & 3 & 4 & 5 & 6 & 7 \\
\hline Not at all & & & & & & $\begin{array}{l}\text { Very } \\
\text { much }\end{array}$ \\
\hline
\end{tabular}

How important is being an American to your sense of identity, overall?

\section{One right answer}

\begin{tabular}{|l|l|l|l|l|l|l|}
\hline 1 & 2 & 3 & 4 & 5 & 6 & 7 \\
\hline Strongly disagree & & & & & & $\begin{array}{l}\text { Strongly } \\
\text { agree }\end{array}$ \\
\hline
\end{tabular}

4 The sooner we all acquire similar values and ideals, the better

15 - I believe there is usually one right way of doing things

11- If two people are arguing about something, at least one of them must be wrong

13- There is usually one right answer to problems

5 - If we cannot achieve agreement on our values we will never be able to keep this society together.

14- I tend to prefer having one right answer, rather than valuing a variety of approaches to an issue

1 An expert who doesn't come up with a definite answer probably doesn't know too much.

7 - "Flexibility in thinking" is another name for being "wishy-washy"

4 - Changing your mind is a sign of weakness.

7 - One should disregard evidence that conflicts with one's established beliefs.

\section{All Items Included in Study 3}

\section{Uncertainty}

Please respond to the following items using the scale below, based on how the passage made you feel

\begin{tabular}{|l|l|l|l|l|l|l|}
\hline 1 & 2 & 3 & 4 & 5 & 6 & 7 \\
\hline $\begin{array}{l}\text { Strongly } \\
\text { Disagree }\end{array}$ & & & & & & $\begin{array}{l}\text { Strongly } \\
\text { Agree }\end{array}$ \\
\hline
\end{tabular}

Right now I feel uncertain

Currently, I'm not sure what to think is right

At this moment, I don't feel sure of what it means to be a Mizzou student

Reading the passage made me feel uncertain about my own views

I currently feel confused about Mizzou student identity 


\section{Meaning in Life}

Please respond to the following items based on how the passage made you feel

\begin{tabular}{|l|l|l|l|l|l|l|}
\hline 1 & 2 & 3 & 4 & 5 & 6 & 7 \\
\hline $\begin{array}{l}\text { Not at all } \\
\text { true }\end{array}$ & & & & & & $\begin{array}{l}\text { Extremely } \\
\text { true }\end{array}$ \\
\hline
\end{tabular}

I understand my life's meaning.

I am looking for something that makes my life meaningful.

I am always looking to find my life's purpose.

My life has a clear sense of purpose.

I have discovered a satisfying life purpose.

I have a good sense of what makes my life meaningful.

I am always searching for something that makes my life feel significant.

I am seeking a purpose or mission for my life.

My life has no clear purpose.

I am searching for meaning in my life.

\section{Mood}

Indicate the extent you the passage made you feel this way

\begin{tabular}{|l|l|l|l|l|l|l|}
\hline 1 & 2 & 3 & 4 & 5 & 6 & 7 \\
\hline Not at all & & & & & & $\begin{array}{l}\text { Very } \\
\text { much }\end{array}$ \\
\hline
\end{tabular}

Anxious

Cheerful

Frustrated

Happy

Pleased

Sad

Enjoyment/Fun

Angry

Worried

\section{Evaluations}

Please respond to the following items about the author of passage you just read, using the scale below

\begin{tabular}{|l|l|l|l|l|l|l|}
\hline 1 & 2 & 3 & 4 & 5 & 6 & 7 \\
\hline $\begin{array}{l}\text { Strongly } \\
\text { Disagree }\end{array}$ & & & & & & $\begin{array}{l}\text { Strongly } \\
\text { Agree }\end{array}$ \\
\hline
\end{tabular}


How much do you agree with the author?

Identity Centrality

\begin{tabular}{|l|l|l|l|l|l|l|}
\hline 1 & 2 & 3 & 4 & 5 & 6 & 7 \\
\hline Not at all & & & & & & $\begin{array}{l}\text { Very } \\
\text { much }\end{array}$ \\
\hline
\end{tabular}

How important is being a Mizzou student to your sense of identity, overall?

\section{The Facets of Meaning}

Using the response scale below, indicate the extent to which you agree or disagree with that statement, based on how you feel right now.

(1) My life makes sense

(2) There is nothing special about my existence ${ }^{a}$

(3) $i$ have aims in my life that are worth striving for

(4) even a thousand years from now, it would still matter whether i existed or not

(5) i have certain life goals that compel me to keep going

(6) $\mathrm{i}$ have overarching goals that guide me in my life

(7) i know what my life is about

(8) i can make sense of the things that happen in my life

(9) $\mathrm{i}$ have goals in life that are very important to me

(10) i understand my life

(11) Whether my life ever existed matters even in the grand scheme of the universe

(12) My direction in life is motivating to me

(13) $\mathrm{i}$ am certain that my life is of importance

(14) looking at my life as a whole, things seem clear to me

(15) even considering how big the universe is, i can say that my life matters

\begin{tabular}{|l|l|l|l|l|l|l|}
\hline 1 & 2 & 3 & 4 & 5 & 6 & 7 \\
\hline Strongly disagree & & & & & & $\begin{array}{l}\text { Strongly } \\
\text { agree }\end{array}$ \\
\hline
\end{tabular}

\section{Conservatism:}

Government is almost always wasteful and inefficient

Government regulation of business usually does more harm than good

Poor people today have it easy because they can get government benefits without

doing anything in return

The government today can't afford to do much more to help the needy

Blacks who can't get ahead in this country are mostly responsible for their own

condition

Immigrants today are a burden on our country because they take our jobs, housing

and health care

The best way to ensure peace is through military strength

Most corporations make a fair and reasonable amount of profit

Stricter environmental laws and regulations cost too many jobs and hurt the economy

Homosexuality should be discouraged by society

\section{Liberalism:}


Government often does a better job than people give it credit for

Government regulation of business is necessary to protect the public interest

Poor people have hard lives because government benefits don't go far enough to help

them live decently

The government should do more to help needy Americans, even if it means going

deeper into debt

$\overline{\text { days }}$

Racial discrimination is the main reason why many black people can't get ahead these

Immigrants today strengthen our country because of their hard work and talents

Good diplomacy is the best way to ensure peace

Business corporations make too much profit

Stricter environmental laws and regulations are worth the cost

Homosexuality should be accepted by society

\section{One right answer}

\begin{tabular}{|l|l|l|l|l|l|l|}
\hline 1 & 2 & 3 & 4 & 5 & 6 & 7 \\
\hline Strongly disagree & & & & & & $\begin{array}{l}\text { Strongly } \\
\text { agree }\end{array}$ \\
\hline
\end{tabular}

4 The sooner we all acquire similar values and ideals, the better

15- I believe there is usually one right way of doing things

11- If two people are arguing about something, at least one of them must be wrong

13- There is usually one right answer to problems

5 - If we cannot achieve agreement on our values we will never be able to keep this society together.

14- I tend to prefer having one right answer, rather than valuing a variety of approaches to an issue

1 An expert who doesn't come up with a definite answer probably doesn't know too much.

7 - "Flexibility in thinking" is another name for being "wishy-washy"

4 - Changing your mind is a sign of weakness.

7 - One should disregard evidence that conflicts with one's established beliefs.

Need for Closure- Intolerance of Ambiguity Sub-Scale

I don't like situations that are uncertain.

I feel uncomfortable when I don't understand the reason why an event occurred in my life.

When I am confused about an important issue, I feel very upset.

I like to know what people are thinking all the time.

I dislike it when a person's statement could mean many different things.

I feel uncomfortable when someone's meaning or intention is unclear to me.

I'd rather know bad news than stay in a state of uncertainty.

In most social conflicts, I can easily see which side is right and which is wrong. 


\section{Intolerance of Uncertainty Scale}

Please use the following scale to indicate how much you agree with each of the following statements

\begin{tabular}{|l|l|l|l|l|}
\hline 1 & 2 & 3 & 4 & 5 \\
\hline $\begin{array}{l}\text { Not at all } \\
\text { characteristic } \\
\text { of me }\end{array}$ & $\begin{array}{l}\text { A little } \\
\text { characteristic } \\
\text { of me }\end{array}$ & $\begin{array}{l}\text { Somewhat } \\
\text { characteristic } \\
\text { of me }\end{array}$ & $\begin{array}{l}\text { Very } \\
\text { characteristic } \\
\text { of me }\end{array}$ & $\begin{array}{l}\text { Entirely } \\
\text { characteristic } \\
\text { of me }\end{array}$ \\
\hline
\end{tabular}

Unforeseen events upset me greatly

It frustrates me not having all the information I need

One should always look ahead so as to avoid surprises

A small unforeseen event can spoil everything, even with the best of planning

When its time to act, uncertainty paralyses me

When I am uncertain, I can't function very well

I always want to know what the future has in store for me

I can't stand being taken by surprise

The smallest doubt can stop me from acting

I should be able to organize everything in advance

I must get away from all uncertain situations

\section{Personal Need for Structure}

Please read each of the following statements and decide how much you agree with each according to your attitudes, beliefs, and experience. It is important for you to realize that there are no "right" or "wrong" answers to these questions. People are different, and we are interested in how you feel. Please respond according to the following scale:

\begin{tabular}{|c|c|c|c|c|c|c|}
\hline 1 & 2 & 3 & 4 & 5 & 6 & 7 \\
\hline $\begin{array}{c}\text { Strongly } \\
\text { disagree }\end{array}$ & & $\begin{array}{c}\text { Neither } \\
\text { agree nor } \\
\text { disagree }\end{array}$ & & & $\begin{array}{c}\text { Strongly } \\
\text { agree }\end{array}$ \\
\hline
\end{tabular}

1.___ It upsets me to go into a situation without knowing what I can expect from it.

2. I__ I'm not bothered by things that interrupt my daily routine. reversed

3. I__ I enjoy having a clear and structured mode of life.

4. I I like to have a place for everything and everything in its place.

5.___ I enjoy being spontaneous. reverse

6. I I I find that a well-ordered life with regular hours makes my life tedious. reverse

7.___ I don't like situations that are uncertain. 
8. I I L hate to change my plans at the last minute.

9. I I L I L wate to with people who are unpredictable.

10.__ I find that a consistent routine enables me to enjoy life more.

11._ I enjoy the exhilaration of being in unpredictable situations. reverse

12. I I become uncomfortable when the rules in a situation are not clear.

\section{Actively Open Minded Thinking Scale}

Please rate the following statements based on the extent to which you agree with them

\begin{tabular}{|l|l|l|l|l|l|l|}
\hline 1 & 2 & 3 & 4 & 5 & 6 & 7 \\
\hline $\begin{array}{l}\text { Strongly } \\
\text { disagree/disapprove }\end{array}$ & & & & & & $\begin{array}{l}\text { Strongly } \\
\text { agree/approve }\end{array}$ \\
\hline
\end{tabular}

1. Allowing oneself to be convinced by an opposing argument is a sign of good character.

2. People should take into consideration evidence that goes against their beliefs.

3. People should revise their beliefs in response to new information or evidence.

4. Changing your mind is a sign of weakness.

5. Intuition is the best guide in making decisions.

6. It is important to persevere in your beliefs even when evidence is brought to bear against them.

7. One should disregard evidence that conflicts with one's established beliefs.

\section{Right-wing Authoritarianism}

Please rate on a scale of 1-7 on how much you disagree or agree of each statement.

\begin{tabular}{|l|l|l|l|l|l|l|}
\hline 1 & 2 & 3 & 4 & 5 & 6 & 7 \\
\hline Strongly disagree & & & & & & $\begin{array}{l}\text { Strongly } \\
\text { agree }\end{array}$ \\
\hline
\end{tabular}


Aggression

1. What our country really needs is a strong, determined leader who will crush evil, and take us back to our true path.

2. Once our government leaders give us the "go ahead" it will be the duty of every patriotic citizen to help stomp out the rot that is poisoning our country from within.

3. The situation in our country is getting so serious, the strongest methods would be justified if they eliminated the troublemakers and got us back to our true path.

4. The only way our country can get through the crisis ahead is to get back to our traditional values, put some tough leaders in power, and silence the troublemakers spreading bad ideas.

Conventionalism

5. There is nothing wrong with premarital sexual intercourse.

6. Everyone should have their own lifestyle, religious beliefs, and sexual preferences, even if it makes them different from everyone else.

7. There is no "ONE right way" to live life; everybody has to create their own way.

8. Gays and lesbians are just as healthy and moral as anybody else. Submission

9. The real key to the "good life" is obedience, discipline, and sticking to the straight and narrow.

10. It may be considered old fashioned by some, but having a normal proper appearance is still the mark of a gentleman, and, especially, a lady.

11. Obedience and respect for authority are the most important virtues children should learn.

12. Our country needs free thinkers who will have the courage to defy traditional ways, even if this upsets many people.

13. Some of the best people in our country are those who are challenging our government, criticizing religion, and ignoring the "normal way" things are supposed to be done.

14. We should treat protestors and radicals with open arms and open minds, since new ideas are the lifeblood of progressive change. 


\section{VITA}

Jake Womick was born in Normal, Illinois and grew up in Illinois, Rhode Island, and Missouri. He graduated from University of Missouri Columbia in Columbia, MO in May 2014 with a Bachelor of Arts degree in psychology. In August 2015, he entered the social/personality psychology program at The University of Missouri Columbia. 